\title{
Liame
}

Histoire et histoire de l'art des époques moderne et contemporaine de l'Europe méditerranéenne et de ses périphéries

$24 \mid 2012$

Territoires urbains en construction dans l'espace méditerranéen à l'époque moderne

\section{Ernest Beulé (1826-1874). Archéologie classique, histoire romaine et politique sous Napoléon III}

\section{Yves Billard et Christophe Chandezon}

\section{OpenEdition}

Journals

Édition électronique

URL : http://journals.openedition.org/liame/277

DOI : $10.4000 /$ liame. 277

ISSN : 2264-623X

Éditeur

CRISES - Centre de Recherches Interdisciplinaires en Sciences Humaines et Sociales de Montpellier

\section{Référence électronique}

Yves Billard et Christophe Chandezon, «Ernest Beulé (1826-1874). Archéologie classique, histoire romaine et politique sous Napoléon III », Liame [En ligne], 24 | 2012, mis en ligne le 05 février 2012, consulté le 21 avril 2019. URL : http://journals.openedition.org/liame/277 ; DOI : 10.4000/liame.277

Ce document a été généré automatiquement le 21 avril 2019

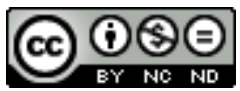

Les contenus de Liame sont mis à disposition selon les termes de la Licence Creative Commons Attribution - Pas d'Utilisation Commerciale - Pas de Modification 4.0 International. 


\title{
Ernest Beulé (1826-1874).
} Archéologie classique, histoire romaine et politique sous Napoléon III

\author{
Yves Billard et Christophe Chandezon
}

1 Dans la nuit du 3 au 4 avril 1874, vers minuit, un homme qui fut l'un des pionniers de l'archéologie française en Grèce et que la politique avait fini par séduire au point de faire de lui un éphémère ministre de l'Intérieur se suicide chez lui, à Paris. Le geste par lequel Ernest Beulé met fin à ses jours est digne de l'Antique. Souffrant depuis quelques semaines d'une douloureuse maladie au cœur, il saisit un poignard d'une panoplie qui ornait sa chambre et se l'enfonce dans la poitrine. Il laisse un mot : « Je souffre trop, c'est encore plus fort qu'au Gymnase ${ }^{1}$; je vais fouiller le siège du mal. Pauvre femme! Pauvres enfants! ». À l'époque, on compara ce geste à celui de Lucrèce qui, elle aussi, s'était percé le cœur, mais pour laver le déshonneur de son viol par l'un des Tarquins. On le sait : pour Rome, le suicide de Lucrèce avait entraîné la chute de la monarchie et son remplacement par la République ${ }^{2}$. La comparaison n'était sans doute pas innocente car Beulé avait œuvré de toutes ses forces, mais sans succès, à la réconciliation entre le comte de Paris et le comte de Chambord et donc à la restauration de la monarchie en France. De cet échec devait naitre la république. La référence au suicide de Lucrèce n'étonne pas: Beulé connaissait sans aucun doute depuis très longtemps les textes fameux de Tite-Live et de Plutarque qui racontaient la mort de l'héroïque Romaine. Elle avait aussi été représentée sur de nombreux tableaux de peintres que Beulé aimait, tels Cranach, Botticelli, Dürer, Véronèse, Rembrandt ou Fragonard. Par les références qu'elle met en œuvre, la mort que Beulé venait de se donner concluait donc avec éclat les carrières de l'archéologue, de l'historien, de l'esthète et du ministre.

Beulé, ministre avons nous dit. Si son nom a conservé encore un peu de lustre, ce n'est pas à la politique, mais à l'archéologie qu'il le doit et aux fouilles menées sur l'Acropole d'Athènes, en 1852-1853. Les visiteurs qui pénètrent sur le rocher sacré d'Athènes passent 
par une porte munie d'une grille. Cette porte s'appelle encore la Porte Beulé3. Pourtant Beulé a bien connu le ministère, dans le cabinet du duc de Broglie où, de mai à novembre 1873, il a assumé le portefeuille de l'intérieur. Mais qui prononce encore son nom lorsqu'il s'agit de parler du long processus qui allait aboutir à la naissance de la $\mathrm{III}^{\mathrm{e}}$ République ? Beulé a donc présenté deux visages successifs : celui de l'archéologue et du professeur, d'abord, celui de l'homme politique ensuite. On pourrait même ajouter qu'il lui est aussi arrivé de revêtir le masque de l'amateur de beaux-arts. De ce dernier aspect de la vie de Beulé, nous ne parlerons guère, car cela mériterait des compétences qu'aucun de nous deux possédons. C'est donc à Beulé archéologue et à Beulé homme politique que nous allons nous intéresser ici, en essayant de montrer comment le second est né du premier.

\section{Athènes et Paris}

Beulé est né à Saumur, dans le Maine-et-Loire, le 29 juin $1826^{4}$. C'était un homme de l'Ouest donc, comme le furent nombre se ses proches. Il fut élève à la rue d'Ulm de 1845 à 1848, obtint l'agrégation de Lettres en 1848 puis devint professeur de rhétorique au collège de Moulins. Il n'y resta que peu de temps, car le 20 septembre 1849, il fut désigné comme l'un des trois nouveaux membres de la $4^{\mathrm{e}}$ promotion de l'École française $\mathrm{d}^{\prime}$ Athènes ${ }^{5}$. Cela lui assurait un traitement non négligeable de 3000 francs par an selon le budget de 1851, mais assorti de l'obligation de résider en Grèce. Or, Beulé tarda à s'y rendre et n'arriva à Athènes, avec ses camarades que le 14 décembre 1849, alors qu'on les y attendait pour octobre. Entre temps, il avait visité la Sicile, sur laquelle il pensait d'abord travailler. Puis il avait fallu se soumettre aux formalités de la quarantaine à Égine. Le directeur de l'École, Amédée Daveluy, fut d'abord tenté de se montrer indulgent, comme il l'avait été avec les membres de la promotion de 1848 qui avaient déjà agi de manière un peu désinvolte, profitant de la désorganisation née de la révolution de février. Tel ne fut cependant pas l'avis du ministre de l'Instruction publique qui souhaita faire un exemple et adressa un blâme et une lettre sévère à Beulé et ses deux camarades ${ }^{6}$. Cette fermeté s'expliquait par le contexte : il s'agissait d'assurer l'avenir de l'École, qui était une création de la Monarchie de Juillet dans ses derniers temps, et qui était aussi menacée pour des raisons budgétaires ${ }^{7}$. 
Fig. 1 : portrait par Baudry, Gazette des Beaux-Arts, $10-2^{\mathrm{e}}$ période (1874), hors texte entre les p. 85-96

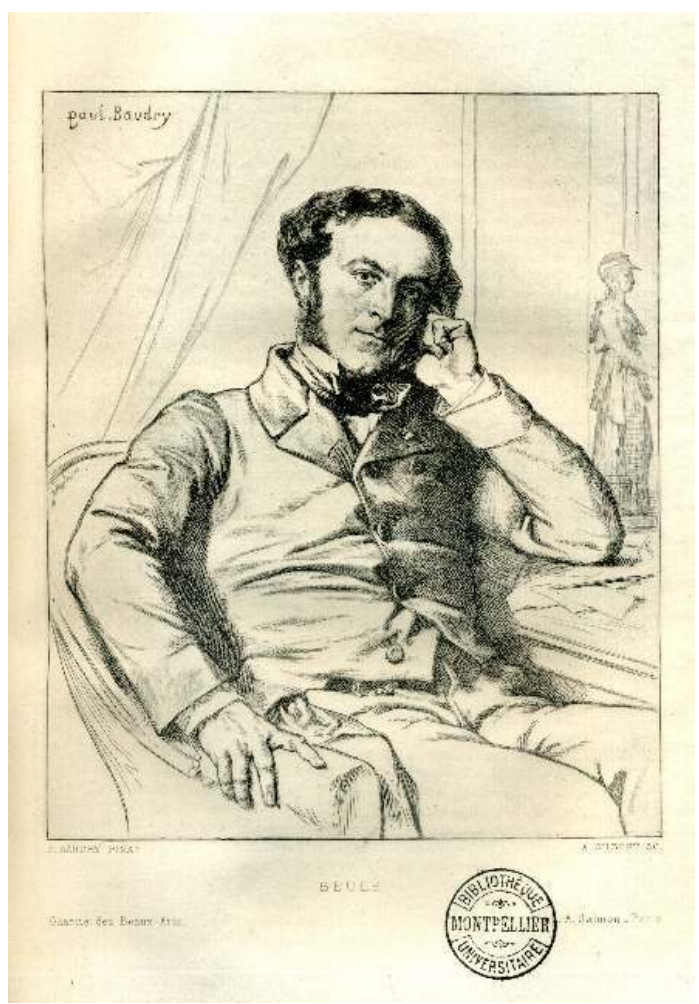

Beulé arriva donc blâmé à Athènes, et à un moment où se jouait le destin de la nouvelle institution. Des mesures essentielles étaient sur le point d'être prises qui allaient l'orienter vers l'archéologie et la placer sous le contrôle de l'Académie des Inscriptions et Belles-Lettres, mettant fin ainsi à une période où les fonctions de l'École étaient rien moins que précises, si ce n'est qu'elle devait renforcer l'influence française en Grèce, dans un contexte de rivalité avec l'Angleterre. En janvier 1850, on exige désormais que les membres de l'École envoient « un mémoire sur un point d'archéologie, de philologie ou d'histoire choisi dans un programme de questions que l'Académie des Inscriptions et Belles-Lettres sera invitée à présenter au Ministère ». Beulé a donc fait partie de la première promotion de membres à devoir se soumettre à cette obligation. Le 7 août 1850, un décret plaçait l'École sous le patronage de l'Académie des Inscriptions, ce qui en marquait encore plus le caractère savant. Beulé, par ses travaux, allait justifier le bienfondé de cette décision ${ }^{8}$.

Le thème du mémoire dont Beulé fut chargé portait sur l'Acropole d'Athènes'. Le rocher était alors en grande partie débarrassé de ses constructions récentes, mais des zones entières du site antique étaient toujours incompréhensibles en raison des ouvrages de défense plus récents. L'espace situé à l'entrée, en contrebas des Propylées, était l'un de ceux qui posaient le plus de problèmes. C'est là que Beulé entreprit une fouille ${ }^{10}$. Il obtint des Grecs l'autorisation de fouiller le 23 février 1852 et le chantier ouvrit le 23 mars avec douze ouvriers recrutés par Kyriakos Pittakis et avec le soutien du ministre de France à Athènes, le baron Forth-Rouen. Il fallut cependant courir sans cesser derrière l'argent pour financer le chantier : Daveluy, le directeur de l'École, n'avait accordé qu'une somme assez maigre et Beulé dut assumer certaines dépenses de sa poche ${ }^{11}$. Une première campagne dura jusqu'en mai 1852, puis une seconde eut lieu de novembre 1852 à avril 
1853. Le chantier attira très vite l'attention, malgré quelques critiques, notamment de l'architecte Chaudet qui avait exposé au salon de 1851 des dessins de l'entrée de l'Acopole et qui avait l'impression que l'on faisait fi de sa propre contribution à la topographie de cette partie du rocher sacré des Athéniens et des sondages qu'avait fait Titeux à l'Acropole en 1845, sondages dont il espérait en vain qu'ils débouchent sur des fouilles en règle ${ }^{12}$. Quoi qu'il en soit, Beulé sut faire la publicité de ses découvertes. Le roi Othon et la reine Amélie de Grèce allèrent le visiter à plusieurs reprises, comme le 3 juillet 1852, ce qui faisait taire les savant grecs qui renâclaient encore. Beulé eut même un temps comme collaborateur le jeune Charles Garnier, alors membre de l'École de Rome et qui devait bâtir plus tard l'opéra de Paris $^{13}$. Les fouilles prirent fin en avril 1853 par la pose de la grille d'entrée puis par l'inauguration le 28 avril d'une stèle avec inscription en souvenir des fouilles de Beulé. On peut toujours la voir, à droite de la porte dite Beulé, à l'intérieur, pour qui pénètre sur l'Acropole. La plaque de marbre qui la porte avait été trouvée lors des fouilles. Le texte, en grec ancien, dit : « La France a mis au jour la porte de l'Acropole, les murs, les tours et l'escalier qui étaient enfouis. Beulé a découvert ${ }^{14}$. 1853. »

Fig. 2 : stèle de l'Acropole d'Athènes commémorant les travaux de Beulé (photo de l'auteur)

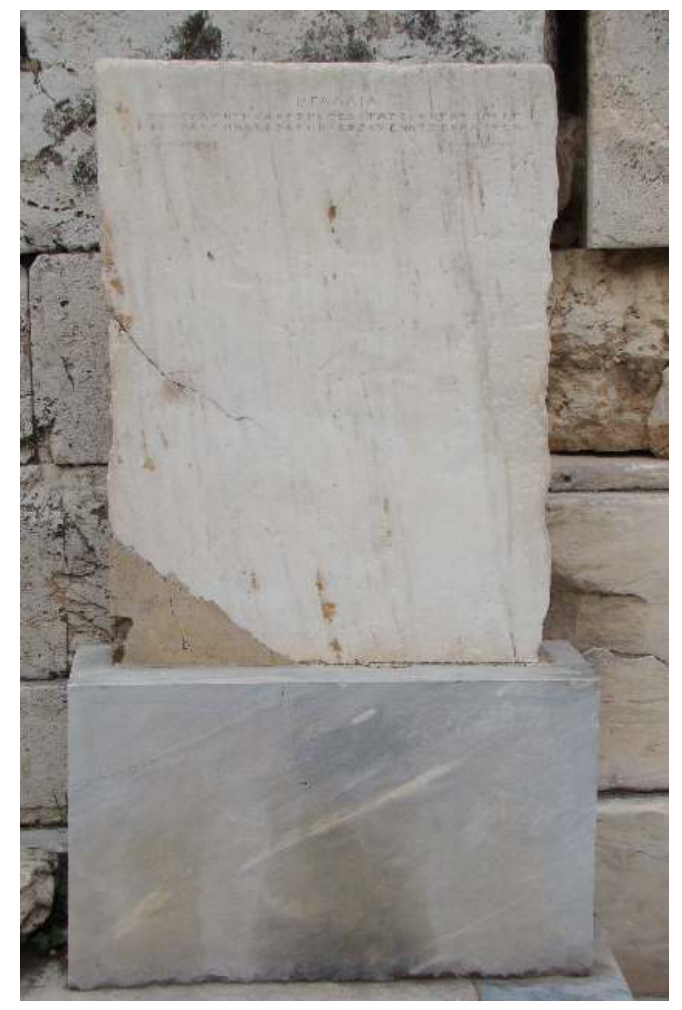

6 Ces fouilles reçurent un bel écho en France et firent connaître le nom de Beulé. La presse s'en fit souvent l'écho ${ }^{15}$ et le ministère de l'Instruction publique l'en félicita, avant et après la proclamation de l'Empire ; il lui accorda aussi de l'argent pour le rembourser des frais engagés et lui permettre de restaurer l'escalier d'accès aux Propylées ${ }^{16}$. Pour l'École française, le bénéfice était réel : elle pouvait désormais justifier de son utilité aux yeux du public. Beulé, de son côté, avant de faire fructifier ce capital de notoriété, devait encore soutenir sa thèse. Ce fut fait à Paris en 1853. L'ouvrage publié aussitôt chez Firmin Didot portait sur le passage du grec ancien au grec moderne et témoigne d'une solide connaissance de cette langue acquise lors du séjour athénien ${ }^{17}$. Les recherches sur l'Acropole firent l'objet de deux publications distinctes. La première prenait la forme d'un 
ouvrage savant formé de deux gros volumes parus en 1853 et 1854, sous le titre L'Acropole $d^{\text {'Athènes }}{ }^{18}$. Beulé $\mathrm{y}$ prend position sur des questions importantes et controversées. Il suggère ainsi une restitution de la Parthénos qui fut vivement combattue ${ }^{19}$. Quatremère de Quincy suggérait au même moment une restitution très différente que le sculpteur Simiart a retenue pour la statue financée par le duc de Luynes et qui fut présentée en 1855 à l'exposition universelle avant d'être installée au château de Dampierre où elle se trouve toujours ${ }^{20}$. Beulé tend aussi à minimiser l'importance de la polychromie dans l'art grec. En cela, il reste un fidèle du classicisme, position esthétique qu'il soutient aussi en matière d'art moderne. Plus tard, en 1862, Beulé publia un second ouvrage sur l'Acropole, en un volume cette fois-ci, et délibérément destiné au grand public ${ }^{21}$.

7 Les années athéniennes furent décisives. Beulé en garda pour toujours un excellent souvenir et une certaine nostalgie ${ }^{22}$. De retour en France, il succéda à Raoul Rochette à la chaire d'archéologie de la Bibliothèque impériale (puis nationale), et resta à ce poste jusqu'à sa mort en 1874. Les années entre 1854 et 1860 sont celles où il gravit une à une les marches de la carrière académique qui vont faire de lui, et à moins de quarante ans, un notable de l'archéologie et des arts. À la Bibliothèque impériale, Beulé donnait un cours annuel d'archéologie, discipline qui incluait alors ce que nous appelons l'histoire de l'art antique. En 1857, il parla de peinture, puis de sculpture en $1858^{23}$. Il était soucieux, afin d'intéresser son public, de toujours lier son approche de l'art antique aux débats contemporains. La première leçon en particulier était destinée à accrocher le public. Selon Beulé, cette méthode avait un avantage : elle « donne à l'archéologie un caractère pratique et militant $»^{24}$. Ce souci demeure constant chez lui. En 1856, il a publié un article sur la comparaison entre les vases chinois et les vases grecs, plutôt favorable aux Grecs et contre les céramiques chinoises dont il trouve les formes trop compliquées ${ }^{25}$. Il prenait ainsi position dans un débat de l'époque ${ }^{26}$. De telles interventions étaient d'autant plus susceptibles de trouver leur écho dans la vie artistique qu'elles participaient au goût archéologique qui marque le Second Empire. Beulé s'inscrivait dans le camp d'un néoclassicisme sur sa fin. Rien d'étonnant donc à ce qu'il apprécie Ingres, qu'il fréquente ${ }^{27}$, et Hippolyte Flandrin, le disciple de ce dernier. Chez tous deux, il admire la façon dont, à la manière des Grecs et même dans un esprit de rivalité avec eux, ils savent utiliser la fresque en l'intégrant étroitement au cadre architectural qui la reçoit. Ingres et Flandrin ne sont pas de simples peintres de plafonds. Beulé le dit dans un opuscule publié en 1860 sur la peinture décorative, nouvel écho de ses $\operatorname{cours}^{28}$. Son goût néo-classique s'accompagnait d'un rejet du néo-gothique. La leçon inaugurale du cours d'archéologie de 1856 est une attaque en règle du style que défendait Viollet-le-Duc au même moment ${ }^{29}$.

Les années 1850 furent aussi celles des études vraiment érudites. Beulé continuait à exploiter les fruits de son séjour athénien, publiant en 1855 un ouvrage sur le

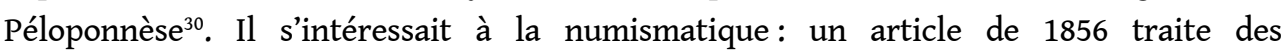
Wappenmünzen, qu'il attribue à Athènes et à l'époque de Pisistrate ${ }^{31}$; l'année suivante, un autre fait le point sur les stéphanéphores et part de leur mention dans les inscriptions athéniennes ${ }^{32}$. Beulé fait le lien avec les monnaies athéniennes du Nouveau style, mais explique encore le nom comme Boeckh, par le voisinage de l'atelier monétaire athénien avec un sanctuaire d'un héros à la couronne dans lequel il propose de reconnaitre Thésée. De ce héros, les Athéniens n'auraient conservé que la couronne intégrée dans leur type monétaire. Ces études sur les monnaies s'appuyaient du reste sur sa collection personnelle et furent synthétisées dans un ouvrage intitulé Les monnaies d'Athènes qui parut en $1858^{33}$. Ce livre au format grand in $-4^{\circ}$ commence avec les monnaies archaïques 
pour aller jusqu'aux émissions athéniennes de bronze de l'époque impériale: Beulé y présentait un catalogue admirablement illustré accompagné de chapitres de synthèse.

Mais il effectue aussi, à la même époque, un retour à l'archéologie de terrain. Au printemps et à l'automne 1859, Beulé entreprend deux campagnes de fouilles à Carthage, entrecoupées par une pause estivale, en raison de la chaleur. Ces fouilles, qu'il publie dès 1861 , s'insèrent dans un contexte de rivalité avec l'Angleterre ${ }^{34}$. Elles sont notamment favorisées par le fait que depuis le règne de Louis-Philippe, la France est propriétaire d'un terrain à Bursa sur lequel elle a fait construire une chapelle dédiée à saint Louis. Là encore, Beulé peut compter sur le soutien des représentants de la France: le consul général de France à Tunis, Léon Roches, lui permit en effet de résider dans sa villa d'été sur le site. Mais, comme à l'Acropole, Beulé dut aussi financer lui-même les premiers travaux, ce qu'il ne manqua pas de faire valoir dès la page de titre de sa publication: Fouilles à Carthage aux frais et sous la direction de M. Beulé. Ses recherches portèrent aussi sur une nécropole de Carthage et sur le port. Elles furent l'occasion de voyages autour de Carthage. Le désir de réitérer le succès d'Athènes est manifeste. En effet, alors que tout le monde pensait que le site de Carthage n'était susceptible de livrer que des vestiges romains, Beulé voulut être le premier à remonter à la Carthage punique. Ce ne fut qu'un demi-succès: il parvint bien à atteindre les couches puniques, mais ne trouva que quelques vestiges de maisons de cette époque. Ces travaux n'en constituent pas moins un tournant dans l'histoire de la recherche archéologique à Carthage, d'autant que Beulé ne fouilla pas pour trouver des œuvres d'art mais pour mieux comprendre le site ${ }^{35}$.

Ces fouilles furent utiles en vue de l'élection à l'Académie des Inscriptions et BellesLettres. Beulé a en effet préparé son entrée à l'Institut. En novembre 1858, il avait déjà posé sa candidature au siège de Félix Lajard, mais l'Académie lui avait préféré Salomon Munk, un spécialiste de la littérature judéo-arabe médiévale ${ }^{36}$. L'année suivante, les fouilles de Carthage lui fournissent l'occasion de se rappeler au souvenir de l'Académie. Dès le 4 février 1859, on lit en séance une lettre de Beulé sur des découvertes faites à Cherchell; le $1^{\text {er }}$ avril, il est question de celles de Carthage et, le 19 août, Charles Lenormant présente un rapport sur le prix de numismatique que Beulé vient de recevoir pour son livre sur les monnaies d'Athènes ${ }^{37}$. On ne pouvait guère ignorer, à l'Académie, le nom de Beulé et l'importance de ses travaux. Une campagne si bien menée finit par porter ses fruits. En novembre 1859, Lenormant qui l'avait soutenu meurt pendant un séjour en Grèce ${ }^{38}$. Le 30 janvier 1860, Beulé pose sa candidature à son siège et le même jour, on lit une nouvelle lettre de lui sur ses fouilles de Carthage. Le 3 février, il est élu contre six autres candidats. C'est un « jeune et savant professeur d'archéologie » - pour reprendre une expression employée par l'Académie elle-même ${ }^{39}$, qui entre au sein de cette vénérable institution. Beulé n'a que trente-quatre ans.

\section{Les Césars contre César}

11 Sa carrière est alors à un tournant. Dans l'immédiat, les fonctions officielles se multiplient : en 1861, par exemple, il est nommé membre de la commission chargée des monuments historiques que préside Prosper Mérimée. Il y côtoie les architectes Duban, Labrouste, Questel et Viollet-le-Duc ${ }^{40}$. Le 12 avril 1862, il est aussi élu secrétaire perpétuel de l'Académie des Beaux-Arts, succédant au compositeur Fromenthal Halévy, ce qui lui impose de prononcer l'éloge des académiciens décédés et lui permet de donner son avis sur certains débats artistiques du temps. Le 3 octobre 1863, par exemple, il prononça 
l'éloge d'Horace Vernet qu'il transforma en apologie du Premier Empire : ses relations avec le régime de Napoléon III n'avaient pas encore pris la tournure négative qu'elles eurent par la suite; il donnait des gages qui n'allaient plus être de mise quelques semaines plus $\operatorname{tard}^{41}$. Il ne devait plus cesser de s'acquitter de cette mission de commémoration des académiciens décédés. Bien plus tard, le 14 décembre 1867, il devait prononcer l'éloge de son ami, Ingres, qui venait de mourir ${ }^{42}$. Il y avait aussi la foule des commissions de moindre importance auxquelles il devait participer en tant que membre de l'Académie des Inscriptions et Belles-Lettres, par exemple la commission de l'École d'Athènes (dès juin 1860) ou celle du prix de numismatique ${ }^{43}$. Tout cela donne à Beulé une indéniable influence dans le milieu de l'archéologie et dans celui de l'art. Ses interventions dans ce dernier domaine lui valent cependant des attaques, par exemple de la part du critique d'art Léon Lagrange, à propos du Salon de 1861, qui s'en prend au dogmatisme de Beulé en matière d'art moderne et à ses critiques contre le système des salons ${ }^{44}$. Beulé défendait la place de l'Institut dans l'organisation des salons, il voulait aussi moraliser le choix des toiles et repousser tout ce qui pourrait faire scandale. Les adversaires de ces théories voyaient dans l'Institut un cénacle de réactionnaires en matière d'art qui, bien que sans la moindre influence sur le mouvement artistique, détenaient néanmoins un pouvoir de nuisance qu'il fallait réduire. On sent, derrière ces controverses, poindre déjà la dispute qui éclatera en 1863, mais aussi certaines attitudes qui se retrouveront chez Beulé ministre de l'intérieur.

Le ton des publications de Beulé change aussi à partir de 1860. De plus en plus il s'adresse à un large public plutôt qu'à ses collègues. Révélateur à cet égard est la publication dans plusieurs livraisons de la Gazette de Beaux-Arts de 1862 d'une pièce de théâtre qu'il intitule Phidias, drame antique. Cette "simple récréation littéraire", pour reprendre les mots de son auteur, a été rédigée à Spa pendant l'été $1860^{45}$ et publiée en volume complet en 1863 , précédée d'une longue introduction qui présente les débats savants ${ }^{46}$. La scène est à Athènes, en 444 avant J.-C. pour la première partie, la seconde en 437, lors des Panathénées, la troisième en 431 . Le but est d'exposer sur le mode d'une conversation presque directe avec les génies du temps (Phidias, Périclès, mais aussi Socrate) ce que Beulé croit percevoir de cette époque ${ }^{47}$. Le procédé n'est pas sans rappeler celui qu'avait employé, à la veille de la révolution, l'abbé Barthélémy dans le Voyage d'Anacharsis.

Avec son Histoire de la sculpture avant Périclès, Beulé revint à une méthode plus courante d'exposition de sa pensée, mais employait le même procédé éditorial que pour sa tentative théâtrale : l'ouvrage parut d'abord en une sorte de feuilleton dans la Gazette des Beaux-Arts entre février 1863 et juin 1864, avant de sortir en livre en $1868^{48}$. Ce livre n'est pas sans mérites puisqu'il montre de la part de son auteur une attention toute particulière aux productions de l'époque archaïque alors mal connues.

À la fin de l'année 1863, éclate l'affaire qui brouille irrémédiablement Beulé avec le régime de Napoléon III. Nous ne ferons ici que la résumer.

Le 30 juin 1863, le comte de Nieuwerkerke avait été nommé surintendant des Beaux-Arts, titre d'Ancien régime qu'on avait ressuscité pour lui et qui lui donnait la haute main sur la politique artistique ${ }^{49}$. Même s'il restait soumis au Ministre de la Maison de l'Empereur, le maréchal Vaillant ${ }^{50}$, il n'en était pas moins protégé par les Tuileries : depuis longtemps, il servait de conseiller artistique à Napoléon III et était en outre l'amant de la princesse Mathilde. Nieuwerkerke avait notamment pour mission de réformer l'École des BeauxArts. Il s'agissait de permettre au pouvoir de se mêler du recrutement des professeurs, mais aussi de modifier en profondeur le programme et de le moderniser. On introduisait 
par exemple des cours de peinture ou de gravure, alors que jusqu'ici seul le dessin était enseigné. Le projet comprenait aussi une réforme du concours ${ }^{51}$. L'École devait ainsi devenir un instrument essentiel de la politique artistique du régime. Le décret impérial du 13 novembre 1863, à la préparation duquel Viollet-le-Duc avait collaboré, précisait tous ces points. Il suscita un tollé dans les Académies et même à l'École des Beaux-Arts puisque, dès le 19 novembre, une délégation de ses élèves se présentait à Compiègne pour remettre à l'Empereur une supplique concernant le récent décret. La réforme privait en effet l'Académie des Beaux-Arts d'une partie de son pouvoir, notamment à propos des prix de Rome. Elle émit une protestation assortie d'un mémoire justificatif, tous deux publiés dans le Moniteur du 6 janvier $1864^{52}$. Beulé, en tant que secrétaire perpétuel de l'Académie des Beaux-Arts, en était le signataire. Dans leur protestation, les académiciens déploraient de ne pas avoir été associés à l'élaboration du texte. Jouant de la comparaison entre les mérites respectifs de l'oncle et du neveu, ils rappelaient aussi que Napoléon I ${ }^{\text {er }}$ avait voulu que l'Empereur soit le Protecteur direct et spécial de l'Institut. Cette réaction de l'Académie des Beaux-Arts ne doit pas surprendre car, depuis 1852, l'Institut n'avait cessé d'être un foyer d'opposition légitimiste et orléaniste ${ }^{53}$. Les affrontements au sujet du décret du 13 novembre furent un moment fort dans l'histoire de cette fronde académique à laquelle la presse ne se priva pas de faire écho. Ils culminèrent le 29 janvier 1864, lors de la leçon inaugurale de Viollet-le-Duc, qui venait d'être nommé professeur à l'École des Beaux-Arts. Le chahut des élèves, mené en présence de Nieuwerkerke et de Théophile Gautier, témoignait du soutien des élèves de l'École aux académiciens ${ }^{54}$.

Face à ces signes de mauvaise humeur, le pouvoir impérial resta ferme et ne se priva pas de rabrouer sans ménagement l'Académie des Beaux-Arts et son secrétaire perpétuel. Une longue réponse émanant du Ministère de Maison de l'Empereur fut publiée elle aussi dans le Moniteur du 6 janvier 1864, juste après la protestation académique ${ }^{55}$. Elle soulignait notamment l'opposition systématique de l'Académie à toute réforme, attitude qui remontait aux régimes ayant précédé le Second Empire. En tant que secrétaire perpétuel, Beulé y répondit sur un ton tout aussi virulent ${ }^{56}$. Il ne partait pas seul au combat puisqu'il pouvait compter sur l'appui d'éminents artistes dont ses amis Ingres et Hippolyte Flandrin. Mais il était difficile de résister efficacement à un pouvoir déterminé à faire appliquer sa réforme. Après quelques concessions, le pouvoir l'emporta et l'atmosphère s'apaisa. Le 17 mars 1864, le comte de Nieuwerkerke prononça même au cimetière Montmartre l'éloge de Fromenthal Halévy, le secrétaire perpétuel qui avait précédé Beulé dans cette fonction. Ce dernier, de son côté, se retira dès lors dans une sorte de bouderie comme en témoigne le fait que, passé le mois de juin 1864, il cessa de publier dans la Gazette des Beaux-Arts, qu'il avait trouvé trop favorable à la réforme. Mais il avait acquis aux yeux d'un large public une stature nouvelle, celle d'opposant au régime. Ce dernier ne s'était pas privé de désigner en Beulé le principal artisan de la résistance de l'Académie et, identifié en tant que tel, ne lui avait pas ménagé les attaques ${ }^{57}$.

À l'occasion, Beulé revint sur la querelle des Beaux-Arts, comme lorsqu'il prononça l'éloge d'Hippolyte Flandrin le 19 novembre 1864. Le peintre avait été l'un des adversaires du décret du 13 novembre 1863. Il avait protesté contre ce texte et on avait laissé entendre que ces funestes réformes avaient hâté sa mort. La séance publique où Beulé prit la parole avait attiré un large public. Ingres était là, enveloppé dans un manteau qui rappelait qu'il avait été récemment malade. Beulé fit des allusions transparentes à la réforme et conclut avec solennité : «Après avoir vécu irréprochable et créé des beautés qui ne périront pas, Flandrin est mort en soldat, défendant les institutions qu'il estimait 
la gloire de son pays. C'était couronner dignement une belle carrière, et l'on ne saurait trop pleurer l'artiste rare et l'homme de bien qui a donné de tels exemples ... Quand même il faudrait désespérer de l'avenir, cette enceinte, qu'entoure la confiance de la nation, demeurera le dernier refuge de l'art désintéressé, le dernier asile des principes spiritualistes, le dernier sanctuaire de l'idéal ${ }^{58}{ }^{\prime}$.

Une deuxième affaire, en 1867, fournit à Beulé l'occasion de manifester son opposition au régime. Au début de cette année, l'empereur avait envisagé de retirer les gisants des Plantagenêts de l'abbaye de Fontevraud pour les offrir à la reine Victoria. La récupération de ces statues était une vieille revendication anglaise. En 1817 déjà, elle avait été présentée à Louis XVIII. En vain. Une nouvelle tentative fut faite à la fin du règne de Louis-Philippe. Le roi des Français choisit de couper court aux pressions de Londres en faisant effectivement retirer les gisants de l'abbaye angevine, mais pour les exposer dans les Galeries historiques de Versailles. Ils regagnèrent cependant Fontevraud en 1849, à l'initiative du prince-président Louis-Napoléon qui pensait ainsi s'attirer la sympathie des populations de l'Ouest. Mais voilà que le 8 février 1867, un envoyé du gouvernement se présenta à l'abbaye, qui servait alors d'établissement pénitentiaire, pour préparer l'envoi de statues à Londres. Le directeur de la prison s'y opposa, faute d'un ordre formel. Le projet de Napoléon III souleva un tollé dans tout l'Anjou. L'évêque d'Angers et de nombreux maires pétitionnèrent contre cette spoliation. Beulé, homme de l'Ouest luimême, s'en mêla et soutint activement les démarches des opposants au transfert. Cette fois, le pouvoir recula et les gisants des Plantagenêts sont toujours à Fontevraud ${ }^{59}$.

La posture d'opposant académique au régime que Beulé assumait décidément, allait faire le succès d'une nouvelle série de livres qu'il destinait au grand public. Il est temps d'en venir au Procès des Césars.

Cette série de livres, qui paraissent de 1867 à 1870, est composée de quatre volumes tous publiés chez Lévy Frères. Le premier tome est intitulé Auguste, sa famille et ses amis. Il sort au printemps 1867. Puis viennent Tibère et l'héritage d'Auguste (printemps 1868), Le sang de Germanicus, consacré à Caligula, Claude et Néron (printemps 1869) et enfin Titus et sa dynastie (printemps 1870). Le programme est donc celui d'une histoire de l'Empire jusqu'à la fin de la dynastie flavienne. On aurait envie de parler d'une histoire des douze Césars (car les éphémères empereurs de 68-69 sont bien évoqués), mais il manque Jules César. Il est deux façons de comprendre cette absence : d'abord, à l'époque de Beulé, il est établi que César n'appartient pas au Principat. Mais il est aussi probable que César avait un statut historiographique particulier dans la mesure où Napoléon III lui-même était en train de rédiger une vie du conquérant romain. Le projet impérial débute vers 1858-1860. Le premier volume en avait paru en $1865 \mathrm{chez}$ Plon, suivi d'un second en 1866 (la suite ne devait jamais voir le jour du temps du Second Empire). Il aurait été difficile à Beulé d'inclure Jules César dans son programme sans se trouver en position d'attaquer de front la personne de Napoléon III, du moins ses idées $^{60}$. Notons au passage une possible incidence du projet de l'empereur sur la vision que Beulé pouvait avoir du régime: Napoléon III, pour rédiger son ouvrage, avait constitué autour de lui une équipe animée par Mérimée et à laquelle participait Victor Duruy, notamment, ainsi que Wilhelm Froehner, Louis Alfred Maury, le bibliothécaire des Tuileries, ou Léon Rénier. Une partie de ces hommes sont des connaissances de Beulé : Maury est en effet sous-bibliothécaire de l'Institut et Léon Heuzey, ancien membre de l'École française d'Athènes et que Beulé avait connu, se vit confier par l'empereur une mission d'exploration en Macédoine ${ }^{61}$. Lorsque Napoléon III rassemble ces hommes autour de lui, vers 1860-1862, Beulé n'a pas 
encore pris parti contre le régime. Il aurait pu être impliqué dans l'entreprise du maître de Tuileries, mais tel ne fut pas le cas. Nous ne pouvons exclure qu'il en ait senti une certaine déception.

21 Jules César est donc exclu, de même que les Antonins. Beulé, qui s'explique sur ce point, suit le jugement de l'historiographie qui voit dans cette époque le moment d'équilibre du Principat après les errements des deux dynasties précédentes: grâce à des princes vertueux, le système a enfin trouvé son équilibre et il n'y a donc plus de procès à faire aux Césars $^{62}$. Mais, d'Auguste à Domitien, pas un seul empereur ne trouve grâce aux yeux de Beulé. Tous sont soit des manipulateurs et des dissimulateurs, soit des monstres. Même Titus est enveloppé dans la condamnation systématique des princes qui ont gouverné Rome. S'il ne paraît pas avoir été un mauvais empereur, c'est parce son règne fut court et que, de 79 à 81, sa personnalité n'eut pas le temps de se révéler sous l'influence néfaste du pouvoir suprême ${ }^{63}$.

Si l'on veut situer ces ouvrages dans les courants historiographiques du temps, il est nécessaire de souligner que l'ensemble ne se présente pas comme un ouvrage destiné à des savants. La quasi-absence de notes ${ }^{64}$, la rareté des renvois aux sources ou à la bibliographie le démontrent. Le ton est d'abord celui d'une causerie devant un auditoire un peu mondain interpellé souvent par un Messieurs qui marque le début de certains paragraphes ${ }^{65}$ ou bien capté par les renvois culturels qu'il attend: la mort de Germanicus entraîne un rappel de la pièce de Racine, de même que l'on évoque les grandes pages de Tacite, comme le meurtre d'Agrippine ${ }^{66}$. Cet aspect s'explique par l'origine de la série que Beulé expose en préface du premier volume: «Ce n'est point un livre que j'offre au public, c'est une série d'entretiens qui ont été sténographiés et qu'on m'a demandé de réunir ». Plus loin, il continue : «Je dédie ces pages à mes auditeurs de la Bibliothèque impériale ; elles leurs appartiennent déjà ... ", ce qui marque bien l'origine du texte ${ }^{67}$. On retrouve d'autres concessions au goût du temps dans ces livres. L'orientalisme par exemple y fait de brèves apparitions au gré de certaines comparaisons. Par exemple à propos des débauches de Caligula: "C'est ainsi que dans la haute Asie et dans l'AsieMineure toutes les religions voluptueuses offrent un mélange de sensualité et de férocité. C'est ainsi que les satrapes de l'antiquité, certains sultans et pachas des temps modernes, ont allié la cruauté la plus effrénée à un état de débauche permanent " ${ }^{68}$. Certains passages apparaissent aussi comme des tableaux historiques puissamment expressifs, équivalents littéraires des grandes peintures historiques de l'époque comme celles de Gérôme: c'est le cas de la proclamation de Claude comme empereur ${ }^{69}$. Enfin, les comparaisons de l'administration impériale avec une machine complexe et presque autonome ne sont pas sans rappeler le contexte de la révolution industrielle ${ }^{70}$.

Une des méthodes de Beulé pour faire revivre les grands personnages de la cour impériale et les empereurs eux-mêmes traduit bien son tempérament et sa formation. À chaque fois que l'occasion s'en présente, il se montre soucieux d'utiliser l'œuvre d'art comme un reflet fidèle $d u$ caractère et une image du régime. Il suit alors une progression systématique : il présente d'abord les portraits monétaires et les gemmes, puis passe aux œuvres de sculpture. Il s'efforce de choisir les documents qu'il estime non les plus réalistes mais les plus révélateurs de la personnalité de tel ou tel prince. Ce sont pour Beulé des témoignages beaucoup plus fidèles que les portraits rédigés par les écrivains ${ }^{71}$. Lorsqu'il veut dessiner le portrait de Messaline, si connue par les textes, il s'explique ainsi : « Les souvenirs sont plutôt vifs sur ce point et notre tâche est de rechercher quelle clarté jettent sur le personnage historique les monuments figurés, et comment le 
témoignage involontaire des artistes fortifie ou contrarie le témoignage réfléchi des écrivains. Les camées, les médailles, les statues qui frappent nos regards nous laissent une impression qui complète l'histoire et fait revivre le type $»^{72}$. La vision qu'il propose au lecteur est avant tout une vision de moraliste plus que d'historien : « Les portraits que je trace sont surtout des études morales et ce sont les enseignements de l'histoire que je m'efforce d'y faire ressortir $»^{73}$. Il dégage donc les « leçons de l'histoire » sans passer par un récit historique classique où la première place serait donnée au fait méticuleusement exposé. Pas de récits exhaustifs de bataille, pas de tableau systématique des institutions ou du contexte chez Beulé qui se situe bien loin de l'histoire romaine telle que l'aborde au même moment Mommsen. Dans l'ensemble, Beulé historiographe est très loin du naturalisme qui, au même moment, est en train d'émerger dans le roman ou la peinture.

Cette histoire de l'empire romain est aussi une histoire du Second Empire, qui plus est une histoire hostile: "Vous ne savez pas quel monstre c'est que l'empire » fait dire Suétone à Tibère, phrase que Beulé s'empresse de reprendre $\mathrm{s}^{74}$. On imagine les réactions du public qui assistait aux conférences de la Bibliothèque impériale et qui, de séance en séance, attendait ce genre de moment. Le républicain Taxile Delord, dans son Histoire du Second Empire publiée quelques années après la chute du régime en a évoqué l'ambiance : "La satire pénétra dans l'archéologie elle-même. M. Beulé, élève de l'École normale et de l'École d'Athènes, avait eu la bonne fortune de découvrir ou de déblayer l'escalier de l'Acropole. Porté par ce hasard heureux au faîte des honneurs académiques, secrétaire perpétuel de l'Académie des Beaux-Arts, rédacteur du Journal des savants, titulaire de la chaire d'archéologie de la Bibliothèque impériale, jouissant de tous les avantages d'une grande position officielle, il brûlait d'y joindre les douceurs de la popularité. On le vit donc tout à coup aiguiser l'allusion archéologique dans sa chaire, et, sous le masque des Césars et des césariens de Rome, faire leur procès au César et aux césariens de Paris. M. Félix Pyet avait eu l'idée, dans les premiers temps de la monarchie de Juillet, de transporter sur la scène de l'Odéon les hommes de son temps déguisés sous des noms et des costumes romains. M. Beulé, usant d'un procédé contraire, changea les Romains du Palatin en Français des Tuileries. Le public nommait de leurs vrais noms Auguste et Tibère, Agrippine et Julie, Agrippa et Mécène, Narcisse et Séjan, tous les personnages livrés à sa malice par le spirituel professeur $\aleph^{75}$. Le procédé n'avait rien de très original : à cette époque, l'histoire, et notamment l'histoire ancienne est une langue couramment employée pour parler du temps présent ${ }^{76}$. Tout le monde comprend et le drapé antique permet de défier les censeurs.

Le contexte intellectuel de cette dénonciation du régime des Césars de l'Antiquité et de celui du César de 1852 est imprégné d'une série de débats à consonance aussi bien politique qu'historiographique apparus vers 1850 et qui ont marqué les vingt années qui suivirent. Ces débats tiennent à la question du césarisme - le mot est nouveau - conçu comme une forme spécifique d'exercice du pouvoir, en opposition avec le régime parlementaire. En France, Napoléon III n'hésite pas à revendiquer ce césarisme ${ }^{77}$ que Beulé combat à un moment où les discussions s'ont en train de s'épuiser. Il emploie le mot de césarisme à plusieurs reprises, notamment dans le dernier volume ${ }^{78}$.

Les allusions à la réalité politique des années 1860 sont présentes dès le premier volume publié en 1867 et ne cessent de se faire de plus en plus claires au fil des années. Le titre lui-même de la série, Le procès des Césars, est limpide, même s'il n'apparaît que tardivement. Les trois premiers volumes en effet ne l'emploient pas et il ne figure qu'en tête du quatrième qui fut publié au printemps $1870^{79}$. Les renvois à l'actualité, les marques 
d'opposition au régime sont aussi plus nombreuses dans les deux derniers volumes, comme si l'audace de Beulé était allée croissant et qu'il s'était pris à son jeu. Mais cette audace est bien relative, car la libéralisation progressive du Second Empire en diminue les risques. Cette évolution politique a commencé en 1860 et s'accélère à partir de 1863 . Les lois de 1868 sur la presse ou la liberté de réunion en marquent l'apogée. C'est donc dans ce contexte que Beulé fait le procès des Césars et celui de César-Napoléon III. Avant d'en étudier les ressorts, répétons que Beulé ne prenait plus guère de risques à étaler ses rancœurs et ses reproches dans ces années où tout le monde pensait la fin du régime imminente. Des démonstrations d'hostilité bien plus virulentes, émanant souvent des républicains, occupaient le devant de la scène, par exemple les articles d'Henri Rochefort dans La Lanterne ${ }^{80}$. Les causes de l'antipathie que ressentait Beulé relevaient d'une autre tradition, celle de la famille conservatrice à laquelle il appartenait. Mais en même temps, il faut aussi observer une sorte d'ironie de la chronologie. C'est dans le quatrième volume de la série que les attaques de Beulé contre le régime sont les plus acerbes. Titus et sa dynastie sort au printemps 1870 et certains passages annoncent la fin imminente du régime, comme ce jugement sur la crise de succession qui s'ouvre à la mort de Néron et voit en quelques mois trois princes portés au pouvoir puis presque aussitôt chassés et tués : «Un demi-siècle s'est à peine écoulé, et déjà les Césars apprennent que la force est un appui précaire et que les armées permanentes se retournent contre ceux qui les payent $\rrbracket^{81}$. Les élections de mai-juin 1869 qui ont vu une nette poussée républicaine, peutêtre même l'assassinat de Victor Noir par le prince Pierre Bonaparte (10 janvier 1870) et les conséquences qu'il entraîne jusqu'en mars expliquent le sentiment d'une chute imminente ${ }^{82}$. C'est pourtant au moment où le dernier volume du Procès des Césars est publié qu'a lieu le plébiscite triomphal du 8 mai qui semble réinstaller le régime sur des bases saines et assurer sa survie. La perspective de la curée s'éloigne. D'autre part, une partie des orléanistes s'est rapprochée du pouvoir lors de la constitution du ministère Émile Ollivier, en janvier ${ }^{83}$. Beulé s'isole donc et se retrouve à contre-courant dans sa famille politique et face à l'opinion. Seule la chute du régime lui donnera raison et transformera son livre en tremplin pour une nouvelle carrière, dans la politique cette fois-ci. Sans Sedan, Beulé aurait sans doute été voué à rester cantonné dans les fonctions qu'il occupait, son opposition aurait été stérile pour sa carrière, sauf à se rallier à son tour.

Les idées politiques qui sous-tendent les quatre volumes du Procès des Césars sont, par bien des points, caractéristiques de celles qui circulent à la fin des années 1860 . Tel est le cas $\mathrm{du}$ reproche fait au régime d'être par naissance illégitime. Les dernières années du Second Empire sont marquées par la réapparition d'un cadavre que l'on croyait oublié et ce cadavre est un souvenir douloureux, comme le péché originel du régime. Les opposants n'hésitent plus à évoquer le " crime de décembre ", c'est-à-dire le coup d'État de 1851, et à le jeter à la figure du pouvoir. La souscription pour ériger un monument à la mémoire du député Baudin, qui avait été tué le 3 décembre 1851 sur une barricade, en est, en 1868, la manifestation la plus évidente ${ }^{84}$. Elle donna lieu à un procès retentissant où s'illustra Gambetta. Beulé fait sans doute allusion au 2 décembre lorsqu'il présente le peuple romain qui, en laissant Auguste instaurer par la force un nouveau régime et en ne s'opposant pas à lui, paye cette passivité de sa liberté : « Dans les attentats contre le pays, il y a deux coupables : celui qui ose et ceux qui permettent, celui qui entreprend et ceux qui souffrent qu'on entreprenne contre les lois, celui qui usurpe et ceux qui abdiquent. Le peuple, en un mot, le peuple romain a été coupable envers la patrie comme envers luimême, le jour où il s'est courbé sous le joug d'Auguste. A-t-il été puni, à son tour, et 
l'histoire a-t-elle consigné son châtiment ?5 $^{85}$ Il y a donc au départ dans cette forme de régime un vice qui rend par essence son évolution et son amélioration impossible. Même avec un prince débonnaire, l'empire resterait mauvais ${ }^{86}$.

L'immoralité fondamentale du régime rejaillit sur le peuple romain. Habitué à vivre dans le luxe, il est sans énergie politique et se contente de s'occuper de ses plaisirs et de ses affaires, perdant tout sens patriotique et tout désir de liberté. Les Romains, à la mort de Caligula, sont désormais incapables de profiter de l'occasion pour reconquérir leur liberté et laissent les militaires choisir un nouvel empereur ${ }^{87}$. Les mots avec lesquels tout cela était expliqué par Beulé ne pouvaient, une fois de plus, que faire songer aux réalités du temps. L'évolution de l'empire se traduit notamment par le rôle prépondérant des affranchis et des femmes, par la place qu'elles prennent désormais dans la vie publique ${ }^{88}$. Là aussi, les auditeurs ne devaient pas avoir de mal à faire l'application de ces passages à leur temps et à déchiffrer les allusions aux affairistes, à la princesse Mathilde et même à l'impératrice.

Il est une autre figure de la rhétorique conservatrice dont Beulé fait usage. Un régime né du renversement des lois est par nature révolutionnaire : « Les révolutionnaires, ce sont ceux qui sapent les bases d'un État régulier pour assurer leur usurpation, violent les lois, font de l'armée un moyen d'oppression, du sénat un instrument avili, du vote libre un mensonge, de la multitude un troupeau mercenaire, et font pénétrer jusqu'au cœur de la nation la corruption, le sommeil et l'oubli d'elle-même. Au contraire, ceux qui veulent que la constitution soit maintenue, les institutions séculaires rétablies, la grandeur de l'Etat poursuivie par un commun effort, la dignité humaine respectée, les droits des citoyens consacrés, les corps constitués souverains, le peuple attaché au bien, au travail, à l'honneur, comme il est attaché au sol de la patrie, ceux-là, dans tous les temps sont les véritables, les seuls conservateurs. Auguste, Tibère et leurs imitateurs, voilà les pires révolutionnaires $»^{89}$. C'est donc par illusion que les conservateurs croient pouvoir s'appuyer sur un pouvoir de ce genre pour obtenir un retour à l'ordre, car ce retour à l'ordre ne saurait être durable. Évoquant les guerres civiles de 68-69, Beulé fait la remarque suivante : «Et les adulateurs du passé osent soutenir effrontément que l'empire était nécessaire pour clore les guerres civiles $!^{90}$ " Cette idée même, selon laquelle le Second Empire est en fait un régime par nature révolutionnaire circule dans l'opposition conservatrice au régime. L'argument est par exemple développé par le député clérical du Haut-Rhin Henri Keller, dans une réponse qu'il adresse en 1861 au prince Jérôme devant le Sénat, à propos de la politique romaine de Napoléon III : « Êtes-vous révolutionnaire ou êtes-vous conservateur $?^{91}$ "

Le système des allusions fonctionne aussi sur un mode presque satirique, par une sorte de travestissement des Parisiens en Romains de l'Empire. La ville de Rome sous Auguste est le miroir du Paris de Napoléon III, c'est-à-dire une ville qui se contente d'être «l'auberge du genre humain ${ }^{92}$ » et renonce à sa liberté. Claude inspectant les travaux de Rome rappelle Napoléon III sur les chantiers parisiens. Mais ce souci édilitaire est une vaine entreprise du pouvoir qui croit ainsi divertir les esprits : « Les princes les plus médiocres se croient grands quand ils inspectent de vastes chantiers où s'agite une légion de maçons, quand ils voient la matière leur obéir, s'accumuler, se dresser jusqu'au ciel pour annoncer à la postérité leur nom avec la ruine de leur peuple ${ }^{93} \%$. Même effet de satire en deux autres passages. Le premier concerne les honneurs votés par les Galates d'Asie Mineure en faveur d'Auguste et qui permettent à Beulé d'envisager " qu'il y eût dans le vieux caractère gaulois un défaut qui a certainement disparu chez leurs descendants 
restés sur le sol français, je veux dire un coupable empressement à se faire courtisan et une tendance aimable à la servilitée ${ }^{94}$ ». Dans le second passage, Beulé s'amuse à faire référence à l'Académie et aux travaux historiques de Napoléon III. C'est à propos des académies dites claudiennes que les Alexandrins avaient fondées afin de procéder à la lecture régulière des ouvrages historiques de l'empereur: "Évidemment les Grecs d'Alexandrie avaient une vertu inconnue aux modernes. Jusqu'ici au moins, quoiqu'il n'ait pas manqué de souverains qui aient écrit l'histoire, il ne s'est point trouvé de corps assez convaincu pour se soumettre à une pareille épreuve ni de peuple assez césarien pour la provoquer ${ }^{95}$ ".

31 Cet effet de travestissement n'empêche pas Beulé de revenir à une question qui lui est chère, celle de la vie artistique et de sa plus ou moins grande vigueur. Une chose lui paraît évidente : un régime qui ne garantit pas la liberté aux créateurs ne peut espérer fonder un art original et durable. Le Siècle d'Auguste n'est qu'un leurre : l'art romain de ce temps n'est pas digne d'admiration, car ce n'est qu'un art d'imitateurs. «Les temps de servilité, où un seul homme commande à un pays, peuvent être des époques brillantes, éclatantes, relativement fécondes, qui s'imposent à l'humanité, qu'on lui fait goûter et admirer ; mais elles ne sont brillantes que par l'extérieur, par la forme, par le don d'imiter. Elles n'inventent pas et sont incapables de rien créer. Il peut y surgir, par hasard, un génie qui lance un jet, mais c'est l'exception. Nous ne saurions trop le répéter, messieurs, les grandes époques pour les arts et les lettres sont et doivent être de grandes époques aussi pour la liberté ${ }^{96} »$. Même les productions du siècle de Louis XIV sont entachées de ce défaut. Des quatre grands siècles de l'art, seuls deux méritent vraiment d'être considérés comme tels, celui de Périclès et le $\mathrm{XV}^{\mathrm{e}}$ siècle italien. Et tous deux sont des temps de liberté, où les républiques ont fleuri. L'idée peut paraitre comme paradoxale chez un orléaniste comme Beulé. Elle témoigne même d'un peu d'inconséquence. Mais cela n'en est pas moins révélateur de cette phase où, communiant dans une même opposition au régime impérial, on voyait républicains, légitimistes et orléanistes se tendre la main les uns aux autres et se réunir autour d'une idée commune, celle de la liberté. Beulé n'est pas pour autant en train de se convertir au républicanisme, car il ne condamne pas par principe le système monarchique. Il reste orléaniste lorsqu'il écrit, dans les dernières pages de Titus et sa dynastie, à propos de la tentative des Flaviens pour créer un pouvoir héréditaire : « Or de quel droit impose-t-on aux hommes le joug d'une famille, c'est-à-dire les hasards redoutables de l'hérédité, si cette famille n'apporte pas avec elle des garanties et des compensations? D'un autre côté, quelle base stable peut espérer une dynastie, si elle ne représente pas un principe ?97 ». C'est donc au prix d'une pirouette que rien ne prépare vraiment qu'il ramène in extremis son raisonnement dans la fidélité à son engagement orléaniste et qu'il évite de justesse la conclusion favorable à la république que tout semblait entraîner.

Alors, quel avenir pour le régime impérial ? La réponse dépend de ce dont on parle. Beulé sait qu'à Rome, le système s'est installé et a duré. À continuer le travail au-delà de la mort de Domitien, sa démonstration contre le régime de Napoléon III n'aurait pas été efficace. Nous avons déjà dit quel est le sens qu'il donne au $\mathrm{II}^{\mathrm{e}}$ siècle comme une période d'équilibre. Mais ce qu'il annonce à son lecteur, c'est la chute prochaine du Second Empire. Les tout derniers mots de Titus et sa dynastie, ceux sur lesquels s'achève la série du procès des Césars se veulent prophétiques : « Toute dynastie sans principes est morte, et la première tempête l'emportera comme la feuille séchée avant la saison ». Certes, tout le monde s'attend à cela dans les premiers mois de 1870 en France. Les soubresauts qui 
marquent la période 1868-1870 et culminent avec l'assassinat de Victor Noir paraissent être des signes annonciateurs clairs: "Ces saturnales de l'usurpation semblent au premier coup d'œil un scandale inutile; elles ont un sens profond cependant pour ceux qui cherchent à dégager les enseignements de l'histoire; elles sont les échelons nécessaires qui font descendre peu à peu le césarisme; elles contribuent à dégoûter les hommes du culte pour un autre homme ${ }^{98} »$. Finalement, il tombe juste, évoquant l'appétit de gloire militaire de Domitien : «La monomanie de la guerre a été la perte de plus d'un souverain et le fléau de plus d'un peuple ${ }^{99} »$.

\section{La tentation politique}

33 Lorsque survient la défaite de Sedan, Beulé a gagné une dimension nouvelle, cette fois dans le domaine politique. Le renouvellement du personnel dirigeant qu'entraîna la chute du Second Empire lui laissait la possibilité de se lancer dans une carrière publique. Beulé est installé à Saumur pendant la guerre de 1870-1871. De là, il organise un service d'ambulances qui permet à des milliers de soldats blessés d'être acheminés en Anjou et en Bretagne vers des hôpitaux moins saturés que ceux qui se trouvaient à proximité des zones de combat. La réussite de cette organisation vaut à Beulé les plus grands éloges ainsi de la part de l'évêque d'Angers dont il était proche - et le fait mieux connaître dans son département natal du Maine-et-Loire où il avait peu séjourné dans les vingt précédentes années ${ }^{100}$.

34 Il n'est donc pas surprenant de retrouver Beulé candidat sur la liste monarchiste conduite par le comte de Falloux en février 1871. Le scrutin de liste départementale étant retenu pour ces élections à l'Assemblée nationale, la présence de Beulé en bonne position sur la liste qui a triomphé dans le Maine-et-Loire suffit à expliquer son élection. Il est impossible de deviner ce qu'aurait été son score personnel au scrutin uninominal dans la circonscription de Saumur. On peut toutefois relever que son positionnement à l'aile droite de l'orléanisme, dans le sillage de Falloux, l'ancien ministre de l'Instruction publique de 1849, trait d'union entre orléanisme et légitimisme, est certainement le plus électoralement favorable en 1871 dans ce département catholique et conservateur.

$35 \mathrm{Au}$ dire de son hagiographe et ami Henry d'Ideville ${ }^{101}$, il aurait passé les premiers mois de son mandat à l'Assemblée de Bordeaux à se justifier face à ceux qui l'accusaient d'être " une créature du dernier régime ", devant tout à Napoléon III : sa nomination à l'Institut puis sa promotion au secrétariat perpétuel de l'Académie des Beaux-Arts et finalement sa chaire d'archéologie à la Bibliothèque impériale. Une telle accusation était profondément injuste. En observant l'évolution politique de Beulé, depuis sa rupture avec «César » en 1863 , on constate au contraire qu'il s'est maintenu dans une opposition intransigeante à l'Empire, même à une époque (1868-1870) où de vieux opposants - et non des moindres comme le républicain Emile Ollivier et surtout Guizot, l'ancien premier ministre de LouisPhilippe, que Beulé admirait ${ }^{102}$ - se ralliaient. C'est alors que Beulé fréquenta assidûment les salons orléanistes restés hostiles à l'Empire, qu'il se lia à Falloux et au duc de Broglie, ses deux parrains en politique.

36 À Bordeaux puis à Versailles, le député Beulé se spécialise dans son domaine de compétence le plus évident. Deux années de suite, il est le rapporteur du budget de l'Instruction publique et des Beaux-Arts. Le 20 mars 1872, il fait un discours remarqué en faveur de l'achèvement des travaux de l'Opéra de Paris (le Palais-Garnier). Tout cela en fait un candidat sérieux à l'emploi de ministre de l'Instruction publique et des Beaux-Arts, 
lors de la formation du gouvernement de Broglie qui suit la chute de Thiers en mai 1873. Sa nomination au ministère de l'Intérieur, le 24 mai, est donc une surprise. Broglie luimême, qui ne donne pas les raisons de son choix, convient d'une erreur de casting. Comme le reconnaît d'Ideville, Beulé "n'avait ni l'improvisation facile ni les connaissances administratives nécessaires pour ce poste. Il le sentait lui-même. $»^{103}$. De mauvaises langues n'ont pas manqué pour prêter à Broglie des intentions tordues. Henry d'Ideville rapporte alors à son ami Beulé qu' « on prétend que le nouveau chef du cabinet (sic $\left.{ }^{104}\right)$, le duc de Broglie, a choisi M. Beulé, afin d'avoir auprès de lui un ministre absolument dévoué et fidèle, sans se dissimuler que ce ministre allait assumer sur lui la tâche la plus rude, la plus pénible, la plus impopulaire ${ }^{105} »$. On peut tout imaginer, jusqu'à supposer que le duc de Broglie aurait choisi Beulé pour les mêmes mauvaises raisons qu'Auguste avec Tibère... Moins farfelue nous paraît une hypothèse prenant en compte l'influence de Falloux. Ce dernier ne pouvait entrer dans un gouvernement en position subalterne vis-àvis de Broglie (plus jeune et plus novice en politique que lui). En donnant à son hommelige un portefeuille régalien, Broglie honore Falloux et s'assure son soutien... Rien cependant ne permet d'étayer cette hypothèse.

Beulé a joué un rôle important aux côtés de Broglie dans les négociations avec les partisans du comte de Chambord, afin de parvenir à un compromis permettant la restauration de la monarchie. À plusieurs reprises, il accompagne Broglie en visite auprès de l'un des représentants en France du comte de Chambord. On sait que la majorité parlementaire qui soutient le gouvernement de Broglie est principalement composée de deux groupes parlementaires : le groupe légitimiste et celui du centre droit, c'est-à-dire les orléanistes, le groupe où siège Beulé. Mais ces deux groupes sont eux-mêmes formés de deux ailes que sépare la perspective d'un compromis entre candidats au trône. À l'extrême droite, les " chevau-légers ${ }^{106}$ ", soit 80 députés (dont Carayon-Latour, Cazenoves de Pradines) qui ne veulent céder sur aucun principe monarchique, quitte à faire échouer la restauration. Face à eux, il existe un groupe de légitimistes modérés (dont le chef de file incontestable est le président de la république Mac-Mahon) qui souhaitent ardemment un accord avec les orléanistes. Ces derniers sont eux-mêmes partagés entre une aile gauche (le duc Decazes, le duc d'Audiffret-Pasquier) qui ne veut rien céder aux légitimistes sur les principes du parlementarisme et ceux (dont Beulé et Broglie luimême) qui sont en quête d'un compromis.

Alors qu'au sein du groupe orléaniste, Decazes semble être l'un des premiers ${ }^{107}$ à avoir dit en public qu'il préférait finalement s'entendre avec les républicains, Beulé, en revanche, s'est fortement impliqué dans les négociations entre royalistes au point d'en faire un combat personnel. On retrouve là un trait de caractère unanimement attribué à Ernest Beulé : homme de convictions, jamais dilettante, il s'implique toujours à fond dans ses combats. Il ne fait aucun doute qu'il a pris l'échec du compromis royaliste, en octobre 1873, pour une défaite personnelle, alors qu'il n'y est évidemment pour rien : s'il faut un responsable, c'est évidemment Chambord lui-même. L'éviction de Beulé du gouvernement par le duc de Broglie le 24 novembre 1873 s'explique en partie par cette nouvelle conjoncture politique: Broglie forme un nouveau gouvernement dans lequel cinq ministres parmi neuf sont nouveaux ou ont obtenu de nouveaux portefeuilles. On remarque que deux orléanistes, Beulé et Batbie, favorables à un compromis royaliste sont remplacés par deux autres, Decazes et Fourtou, de l'aile opposée du groupe parlementaire. L'échec du compromis monarchique et l'éviction de Beulé du ministère, n'expliquent pas son suicide en 1874 , mais contribuent à ce sentiment d'amertume, cette 
mélancolie qui se sont emparées de lui alors. Il s'est retrouvé aller contre le sens de l'Histoire et ne s'en est pas vraiment remis.

39 Mais l'explication la plus vraisemblable à la démission du ministre Beulé en novembre 1873 est à rechercher dans le bilan désastreux de son action au ministère de l'Intérieur. Premier des ministres de l'Intérieur de l'Ordre moral, Beulé s'est voulu un ministre à poigne, sans souci d'être populaire. Dès les premières semaines de son ministère, il révoque de nombreux préfets, s'attirant les critiques de l'opposition, bien que ce mouvement soit très en-deçà de ce qu'on a pu observer en 1871 ou en 1877. Face aux critiques et aux assauts de l'opposition, Beulé n'a pas la manière. Lui rendant hommage sur sa tombe, Broglie a pu dire : « toujours prêt à se jeter dans la mêlée pour sa cause, il ne recula jamais devant un acte qu'il croyait juste, par crainte de se créer un ennemi ou le désir de s'épargner un outrage ${ }^{108} »$.

40 C'est dans sa tentative de mise au pas de la presse républicaine que Beulé a essuyé les échecs les plus graves et forgé sa réputation d'incompétence. Un ministre décidé à réprimer la presse d'opposition dispose alors ${ }^{109}$ d'un arsenal de 57 incriminations définies dans 42 textes législatifs (lois ou décrets) accumulés depuis la Restauration. Cet entrelacs législatif est d'un maniement complexe et délicat, il demande à être mis en œuvre avec compétence et discernement. Lambrecht, Casimir-Périer ${ }^{110}$, Lefranc et Goulard, les ministres de l'Intérieur de la présidence de Thiers (1871-1873) ont montré quels résultats on pouvait obtenir, à condition d'avoir des objectifs réalistes et d'employer des méthodes appropriées. Ils étaient, certes, à bonne école, Thiers lui-même ayant été un journaliste persécuté sous la Restauration puis un ministre de l'Intérieur persécuteur de journalistes sous la monarchie de Juillet. Leur cible principale, sinon unique, était la presse socialiste parisienne, qu'ils parvinrent à anéantir presque entièrement en deux ans. Pour cela, ils firent usage d'un arsenal répressif allant de l'amende à l'interdiction en passant par la suspension (de 15 jours à 3 mois). En 27 mois, les ministres de Thiers ont pris 217 mesures répressives contre la presse. Beulé et son successeur immédiat (Broglie lui-même), 270 en un an seulement! Sous l'autorité de Beulé, le Bureau de la Presse, une direction du ministère de l'Intérieur installée à Paris ${ }^{111}$, a ses 31 agents accablés de travail. Il réussit même l'exploit de censurer un numéro de la Gazette de France - un journal légitimiste ! parce qu'il reproduisait une circulaire de l'Internationale. C'était évidemment pour la critiquer mais, visiblement surmenés, les agents du Bureau de la Presse ne s'en rendirent même pas compte et censurèrent ce journal avec la même stupidité mécanique qu'un logiciel de correction orthographique des années $1990^{112}$.

41 Ces dysfonctionnements du ministère de l'Intérieur ne tardent pas à se retrouver sur la place publique. Beulé ne contrôle pas les fonctionnaires du ministère, en majorité républicains. Il en va ainsi dans tous les ministères. Le pire étant le ministère de la Guerre, resté un bastion bonapartiste. Les autres ministres le savent et y font attention. Beulé, en revanche, est à deux reprises victime de fuites. Le 10 juin 1873, Gambetta lit à la tribune de l'Assemblée nationale une circulaire confidentielle demandant aux préfets «un rapport sur la presse de [leur] département». La circulaire présentait les instructions suivantes: "Dites-moi les journaux conservateurs ou susceptibles de le devenir, quelle que soit la nuance à laquelle ils appartiennent, leur situation financière et le prix qu'ils pourraient attacher au concours bienveillant de l'administration ». Beulé se défend très maladroitement devant Gambetta et la solution retenue par le gouvernement de Broglie (la démission du sous-secrétaire d'État à l'Intérieur Ernest Pascal) n'améliore pas la réputation de Beulé. Trois mois plus tard, en septembre, une nouvelle fuite révèle 
que Beulé envisage de prolonger (au moins dans le département des Vosges) la législation imposée par les Allemands dans l'Est de la France. Dans les départements occupés depuis 1871, les Allemands avaient laissé une assez grande liberté à la presse locale mais interdit la diffusion des journaux du reste de la France. Situation qui convenait à merveille aux gouvernements de Versailles : la presse dite rouge n'arrivait pas dans les départements de l'Est. Mais le ministre de l'Intérieur déplorant implicitement la fin de l'occupation allemande, quelle maladresse !

42 frappa à la porte sans obtenir de réponse. Il avertit Mme Beulé qui fit la funèbre découverte. Le suicide ne faisait aucun doute mais on parla d'une rupture d'anévrisme ${ }^{113}$. Cela permit de faire à Beulé de somptueuses funérailles célébrées le 9 avril à SaintGermain-des-Prés, en présence d'un incroyable parterre de ministres, de députés et de savants. On l'enterra au Père-Lachaise : son tombeau s'y voit encore, situé dans l'un des endroits les plus en vue de la grande nécropole parisienne, au bord de la grande allée centrale. Ce spécialiste de l'Antiquité repose dans une copie du tombeau de Scipion Barbatus, l'un des plus célèbres sarcophages romains. L'inscription rappelle sa double carrière: «Beulé. Membre de l'Institut. Secrétaire perpétuel de l'Académie des Beaux Arts. Député. Ancien ministre de l'Intérieur. MDCCCXXVI + MDCCCLXXIV ». Beulé laissait une femme veuve et deux fils orphelins. Dans les jours qui suivirent, des rumeurs sur la nature de sa mort et sur les causes de son geste commencèrent à circuler dans Paris. On parla même d'ennuis financiers, de placements boursiers qui avaient mal tourné. Il fallut avouer la réalité du suicide ${ }^{114}$.

Que reste-t-il de Beulé aujourd'hui ? Les histoires du Second Empire l'ignorent et il est à peine mentionné dans les ouvrages consacrés à la III ${ }^{e}$ République naissante. Sa participation, certes indirecte et modeste, à la vie artistique de la France des années 1850-1860, n'a laissé aucun souvenir. Si le nom de Beulé est encore évoqué de nos jours, c'est grâce à ses travaux d'archéologue : à l'entrée de l'Acropole d'Athènes, la Porte Beulé s'appelle toujours ainsi. C'est un honneur bien singulier pour une archéologue que de voir son nom attaché à un monument qu'il a étudié. Dans le cas de Beulé, ce privilège est d'autant plus éclatant que ce monument est un des plus insignes qui soit. C'est donc l'archéologie qui sauve Beulé de l'oubli, non sa carrière politique. Elle n'a pas été ingrate avec lui, en fin de compte. Nous osons croire que c'est sans doute ce que Beulé lui-même aurait souhaité. 
Fig. 3 : tombe de Beulé au Père-Lachaise

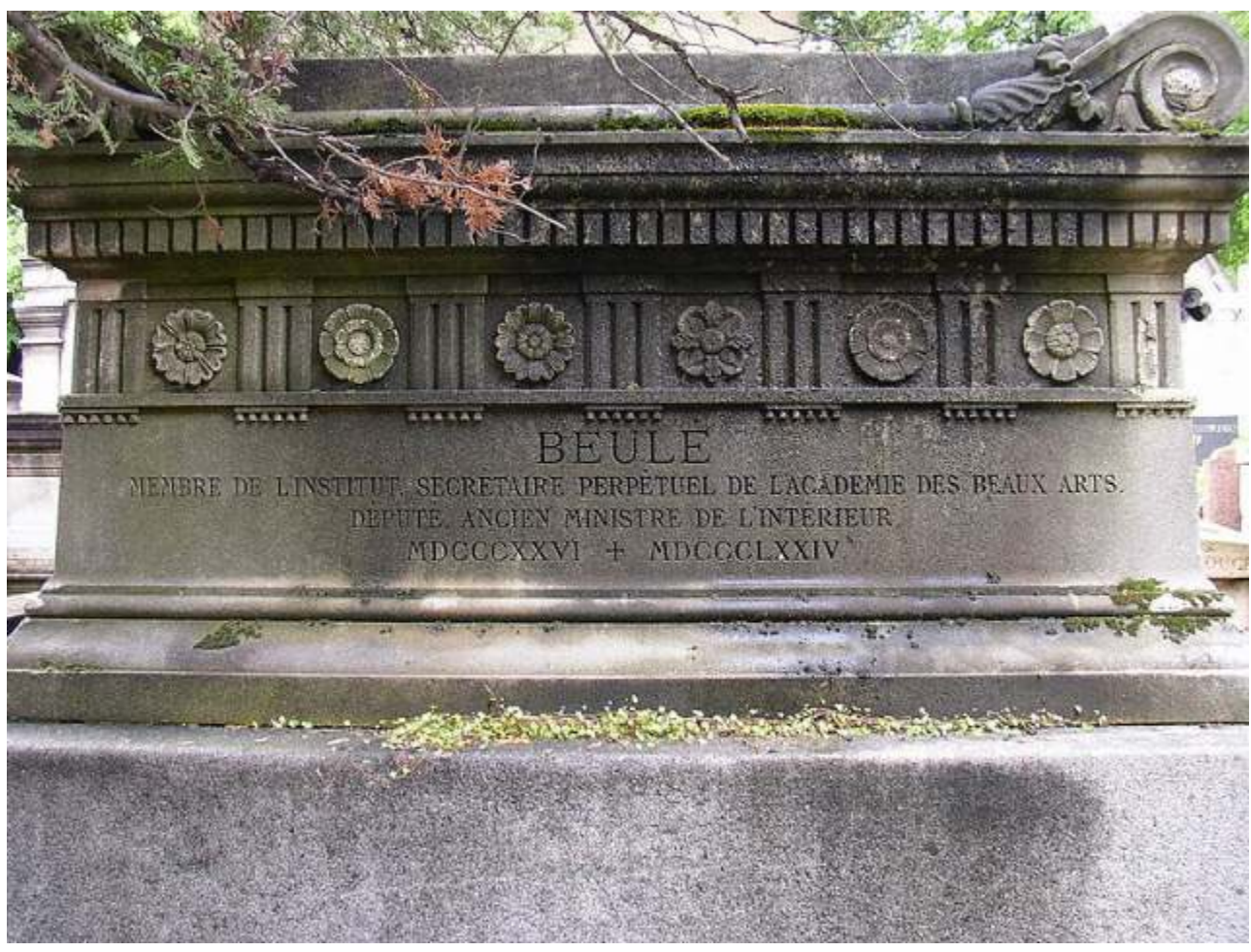

\section{BIBLIOGRAPHIE}

ABOUT, Edmond (1854) : La Grèce contemporaine, Paris, L. Hachette.

ALBERT, Pierre (1980) : Histoire de la Presse nationale au début de la III ${ }^{e}$ République, 1871-1879, Paris, Honoré Champion.

Baedeker's Griechenland (1908) : Leizpig, K. Baedeker.

BAGULEY, David (2000) : Napoleon III and His Regime. An Extravaganza, Baton Rouge, Lousiana State University Press.

BEULÉ, Charles-Ernest (1853a) : L'acropole d'Athènes, Paris, F. Didot frères, 2 vol.

BEULÉ, Charles-Ernest (1853b) : An vulgaris lingua apud veteres Graecos existiterit ?, Paris, F. Didot. BEULÉ, Charles-Ernest (1855) : Études sur le Péloponnèse, Paris, F. Didot frères.

BEULÉ, Charles-Ernest (1856a) : «Les vases chinois et les vases grecs », Revue des Deux Mondes, livraison du $1^{\mathrm{er}}$ décembre, p. 556-580.

BEULÉ, Charles-Ernest (1856b) : « Les monnaies de Solon et de Pisistrate », Revue numismatique, nouvelle série, 1 , p. 345-368 et pl. XI. 
BEULÉ, Charles-Ernest (1856b) : «Le stéphanéphore (monnaies d'Athènes) », Revue numismatique, nouvelle série, 2 , p. 90-114 et pl. IV.

BEULÉ, Charles-Ernest (1858a) : Cours d'archéologie. Discours d'ouverture (Bibliothèque impériale), Paris, F. Didot frères.

BEULÉ, Charles-Ernest (1858b) : Les monnaies d'Athènes, Paris, Rollin.

BEULÉ, Charles-Ernest (1860) : La peinture décorative et le grand art, (Cours d'archéologie), Paris, F. Didot.

BEULÉ, Charles-Ernest (1861) : Fouilles à Carthage aux frais et sous la direction de M. Beulé, Paris, Imprimerie impériale.

BEULÉ, Charles-Ernest (1862a) : L'Acropole d'Athènes, nouvelle édition, Paris, F. Didot frères.

BEULÉ, Charles-Ernest (1862b) : « Le jour des Panathénées », Gazette des Beaux-Arts, 12, avril, p. 321-349.

BEULÉ, Charles-Ernest (1862c) : « Socrate ou l'esprit critique », Gazette des Beaux-Arts, 13, août, p. 126-133.

BEULÉ, Charles-Ernest (1863) : Phidias, drame antique, Paris, L. Hachette.

BEULÉ, Charles-Ernest (1867) : Auguste, sa famille et ses amis, Paris, Michel Lévy frères.

BEULÉ, Charles-Ernest (1868a) : Histoire de l'art grec avant Périclès, Paris, Didier.

BEULÉ, Charles-Ernest (1868b) : Tibère et l'héritage d'Auguste, Paris, Michel Lévy frères.

BEULÉ, Charles-Ernest (1869a) : Phidias, drame antique, $2^{2}$ édition, Paris, Didier.

BEULÉ, Charles-Ernest (1869b) : Le sang de Germanicus, Paris, Michel Lévy frères.

BEULÉ, Charles-Ernest (1870) : Titus et sa dynastie, Paris, Michel Lévy.

BEULÉ, Charles-Ernest (1872) : Le drame du Vésuve, Paris, Michel Lévy frères.

BEULÉ, Charles-Ernest (1873) : Fouilles et découvertes résumées et discutées en vue de l'histoire de l'art, Paris, Didier, 2 vol.

BLANC, Charles (1861) : «Le tombeau de M. Lenormant », Gazette des Beaux-Arts, 9 (1861),

p. 167-173.

BLANC, Charles (1870) : Ingres, sa vie et ses ouvrages, Paris, Vve J. Renouard.

BLANC, Charles et HOUSSAYE, Edouard (1860) : chronique des nouveautés artistiques (sans titre), Gazette des Beaux-Arts, 5 (1860), p. 254-256.

BLANC, Charles et HOUSSAYE, Edouard (1861) : chronique des nouveautés artistiques (sans titre), Gazette des Beaux-Arts, 9 (1861), p. 62-64.

CHAUdet, A. (1852) : «Propylés de l'Acropole d'Athènes », Revue archéologique, p. 288-298.

CRAI (1862a) : Académie des Inscriptions et Belles-Lettres. Comptes-rendus des séances de l'année 1859, (CRAI, 3), Paris.

CRAI, 4 (1862b) : Académie des Inscriptions et Belles-Lettres. Comptes-rendus des séances de l'année 1860, (CRAI, 4), Paris.

DANSETTE, Adrien (1972) : Le Second Empire. Du 2 décembre au 4 septembre, Paris, Hachette. 
DARCEL, Alfred (1863) : « Les arts industriels à l'exposition de Londres », La Gazette des Beaux-Arts, 14, p. 64-86.

DELORD, Taxile (1876) : Histoire du Second Empire : 1848-1869, 2éd., Paris, G. Baillière.

École impériale (1863) : « École impériale et spéciale des Beaux-Arts », Gazette des Beaux-Arts, 15, p. 563-572.

Documents (1864) : « Documents relatifs à l'École impériale et spéciale des Beaux-Arts », Gazette des Beaux-Arts, 16, p. 267-296.

ÉTIENNE, Roland (1996) : « L'École française d'Athènes, 1846-1896 », Bulletin de Correspondance Hellénique, 120, p. 3-22.

FRANQUEVILLE, Charles Franquet comte de (1895) : Le premier siècle de l'Institut de France. 25 octobre 1795-25 octobre 1895, vol. 1 (Histoire, organisation, personnel. Notices biographiques et bibliographiques sur les académiciens titulaires), Paris, J. Rothschild.

GIRARD, Louis (1986) : Napoléon III, Paris, Fayard.

GLACHANT, Paul et Victor (1899) : « Une lettre inédite d'Ernest Beulé », Revue des Etudes Grecques, 11, p. 1-8.

GUIGNIAUT, Joseph-Daniel (1852) : «Lettres de M. Guigniaut à M. le Ministre de l'Instruction publique, sur les découvertes faites récemment à Athènes ", Revue archéologique, $2^{\mathrm{e}}$ partie, p. 241-245.

HoltzMAnN, Bernard (2003) : L'Acropole d'Athènes. Monuments, cultes et histoire du sanctuaire d'Athéna Polias, Paris, Picard.

GRAN-AYMERICH, Eve (2001) : Dictionnaire biographique d'archéologie (1798-1945), préface de Jean Leclant, Paris, éd. du CNRS.

Grèce I (1896) : Grèce. I. Athènes et ses environs, Paris, Guide-Joanne.

GRUYER, François-Anatole (1874) : « Beulé, secrétaire perpétuel de l'Académie des Beaux-Arts », Gazette des Beaux-Arts, $10-2^{\mathrm{e}}$ période, p. 85-96.

GSELL, Stéphane (1920) : Histoire ancienne de l'Afrique du nord, t. II : L'Etat Carthaginois, Paris, Hachette.

IDEVILLE, Henry d' (1874) : M.Beulé, Souvenirs personnels, Paris, Michel Lévy.

LAGRANGE, Léon (1861) : « Salon de 1861 », Gazette des Beaux-Arts, 10, p. 193-211.

LANCEL, Serge (1992): Carthage, Paris, Fayard.

LECLANT, Jean (1996) : « L'École française d'Athènes et l'Académie des Inscriptions et BellesLettres : des relations fructueuses au profit des études grecques ", Bulletin de Correspondance Hellénique, 120, p. 51-68.

LENIAUD, Jean-Michel (2003) : Charles Garnier, Paris, Monum, 2003.

LENORMANT, François (1860) : « La Minerve du Parthénon », Gazette des Beaux-Arts, 8, p. 129-150, 202-227 et 278-294.

Mémoires du duc de Broglie (1938) : Paris, Calmann-Lévy.

MILZA, Pierre (2004) : Napoléon III, Paris, Perrin.

NICOLET, Claude (2003) : La fabrique d'une nation. La France entre Rome et les Germains, Paris, Perrin. 
Nieuwerkerke (2000) : Le comte de Nieuwerkerke. Art et pouvoir sous Napoléon III, catalogue de l'exposition de Compiègne, oct. 2000-janvier 2001, Paris, Réunion des musées nationaux.

Paris-Rome-Athènes (1982) : Paris-Rome-Athènes. Le voyage en Grèce des architectes français au $\mathrm{XIX}^{\mathrm{e}}$ et $\mathrm{XX}^{\mathrm{e}}$ siècles, Paris, Ecole nationale supérieure des Beaux-Arts.

PREVOST, Michel et ROMAN D'AMAT, Jean-Charles (1954) : Dictionnaire de biographie française, Paris, Letouzey et Ané, t. 6, p. 362-363.

RADET, Georges (1901): L'histoire et l'œuvre de l'École française d'Athènes, Paris, Fontemoing.

TULARD, Jean (dir.) (1995) : Dictionnaire du Second Empire, Paris, Fayard.

VALENTI, Catherine (2006) : L'École française d'Athènes, Paris, Belin.

\section{NOTES}

1. C'est un théâtre où, en février 1874 , Beulé avait déjà subi une violente attaque de sa maladie.

2. Les récits le plus célèbre du suicide de Lucrèce sont dans Tite-Live et dans Plutarque.

3. Parmi la multitude des guides de la Grèce, nous renvoyons au Guide-Joanne, Grèce I, 1896, p. 47-48, avec mention et explications des fouilles de Beulé. Le nom s'est imposé dans toutes les langues et le Baedeker's Griechenland, 1908, p. 39, décrit lui aussi «das Beulé'sche Tor » et évoque le souvenir de son fouilleur ; il renvoie même à la plaque commémorative).

4. Outre les ouvrages de Beulé lui-même (que je citerai en cours de travail), nous avons utilisé les synthèses suivantes : Gruyer, 1874 ; Prevost \& Roman d'Amat, 1954 ; Gran-Aymerich, 2001, p. 71.

5. Ses deux camarades étaient Alexandre Bertrand (1820-1902 : il dirigea longtemps le musée de Saint-Germain-en-Laye) et Alfred Mézières (1826-1915 ; lui aussi, comme Beulé, fit de la politique, et devint sénateur) : voir Radet, 1901, p. 450.

6. Archives de l'École française d'Athènes, carton administration 2.0, utilisé ici et pour tout ce qui concerne les premiers temps de Beulé à l'École. Sur le passage de Beulé à l'EFA, voir aussi Valenti, 2006, p. 36.

7. Sur les premiers temps de l'École française d'Athènes, voir d'abord Radet, 1901, p. 37-94. On lira aussi avec plaisir les pages ironiques (et exagérées) d'About, 1854, chap. II, p. 10 : «Les premiers [membres] qui débarquèrent en Grèce furent assez embarrassés : ils ne savaient pas précisément ce qu'ils venaient y faire. Les uns se mirent à apprendre le grec moderne avec un vieux professeur que la France payait fort bien; les autres s'amusèrent à enseigner le français à quelques étudiants de l'université d'Athènes; les uns voyagèrent, les autres restèrent au logis ; tel prépara de grands travaux, tel autre ne fit rien, ou peu de choses ». Rappelons qu'Edmond About a été membre de la promotion 1851 de l'École : il a donc côtoyé Beulé. L'histoire de ces premières années de l'École a depuis été de nouveau présentée dans plusieurs des articles publiés dans le volume du BCH marquant les 150 ans de l'EFA (Étienne, 1996; Leclant, 1996) et dans Valenti, 2006, p. 21-39.

8. Edmond About insiste sur le rôle déterminant de ce dernier : About, 1854, chap. II, p. 10 : «Son nom acquit en peu de moins une grande célébrité, dont il retomba quelque chose sur l'école. L'émulation s'empara de nos jeunes professeurs; Athènes leur parut un séjour plus désirable que Chaumont ou Poitiers, et les places vacantes se remplirent comme par enchantement». Sur l'importance de ce tournant dans l'histoire de l'École, voir Radet, 1901, p. 95-108.

9. Sur les circonstances de ce choix, voir Glachant, 1899.

10. Pour l'histoire de cette fouille, voir Beulé, 1873, vol. 1, p. 3-77 (« Journal de mes fouilles»). Ce texte a cependant peut-être été profondément retravaillé pour la publication. Il comporte en effet des allusions à l'actualité politique du temps, notamment au coup d'État du 2 décembre 
1851, qui semblent déplacés dans un texte de ce genre. Par exemple, le 12 mars 1852, alors que le sculpteur David d'Angers vient de débarquer avec sa fille au Pirée, fuyant le nouveau régime, Beulé commente ainsi l'événement : «Jamais la violence et la proscription ne m'étaient apparues sous une forme aussi odieuse. L'ostracisme a une excuse lorsqu'il atteint des prétendants ou des ambitieux funestes à leur pays. Mais frapper un grand talent, interrompre sa carrière, chasser avec lui les belles œuvres d'art dont il aurait continué à orner sa patrie, un crime peut à peine justifier une telle rigueur!» (p. 67-68). Radet, 1901, p. 116-120, et p. 272-281 sur les fouilles de Beulé aux Propylées. Sur le contexte des premières fouilles de l'Acropole, Holtzmann, 2003, p. 261-263.

11. Radet, 1901, p. 118 et n. 7.

12. Les fouilles de Beulé nécessitèrent aussi d'écarter l'architecte Alfred Chaudet qui continuait les travaux de Philippe Titeux aux Propylées : sur ses envois de Rome, voir Paris-Rome-Athènes, 1982, p. 172-177. Chaudet protesta contre la publicité donnée par Beulé à ses fouilles dans la Revue archéologique: Chaudet, 1852. Il avoue qu'il « ne voit pas avec plaisir dépouiller la part qui lui revient $»($ p. 289).

13. Voir Leniaud, 2003, p. 29-38. Beulé eut aussi l'occasion de fréquenter Garnier à Rome, pendant un séjour qu'il fit à l'Académie de France, à l'automne 1851. Il y connut aussi les peintres Alexandre Cabanel et Paul Baudry (Radet, 1901, p. 242 et n. 5). Beulé et Garnier demeurèrent liés par la suite et Beulé soutint l'architecte. Garnier fit aussi la connaissance d'Edmond About à l'occasion de ce séjour: tous deux travaillèrent à Égine et restèrent amis. Sur les envois de Garnier concernant le temps d'Égine : Paris-Rome-Athènes, 1982, p. 214-223.

14. Cette inscription ne figure pas, naturellement, dans les corpus des inscriptions de l'Acropole. Elle a été gravée en stoichédon, avec des lettres imitant celles du IV ${ }^{\mathrm{e}}$ siècle av. J.-C. La deuxième phrase, celle qui donne le nom de Beulé, est en lettres plus petites. Texte dans Beulé, 1853a, vol. 1, p. 8 , où il explique : « Le voyageur qui franchit le seuil de la nouvelle entrée remarquera, à sa droite, une grande plaque de marbre scellée contre le mur ; sous cette plaque, après quarantetrois jours de recherches vaines, j'ai enfin trouvé les traces antiques que je poursuivais. Je l'ai choisie pour recevoir l'inscription suivante » (suit le texte grec).

15. Voir par exemple l'annonce du résultat de ces fouilles au ministre de l'Instruction publique par Joseph Guigniaut, qui exerçait provisoirement la fonction de secrétaire de l'Académie des Inscriptions et Belles-Lettres par des lettres datées du 19 et 20 juin 1852 : Guignaut, 1852.

16. Lettre du 24 juin 1852 et lettre du 28 avril 1853 (dans le même carton des archives de l'EFA).

17. Beulé, 1853b. L'ouvrage fait 56 pages.

18. L'ouvrage fut publié chez Firmin-Didot Frères, le premier volume comporte 356 pages, le second 392.

19. Voir par exemple les réactions négatives de Lenormant, 1860, notamment p. 142 et sq.

20. Voir la réaction de Beulé, dans la Revue des Deux Mondes du $1^{\mathrm{er}}$ février 1856.

21. Beulé, 1862a, chez Firmin Didot.

22. Beulé, 1869a, p. I-IV : cette œuvre est conçue comme un souvenir de «ma chère Athènes, où se sont écoulées les quatre plus belles années de ma vie ». L'attention qu'il porta ensuite à l'École témoigne aussi cet attachement. Nous expliquerons plus loin qu'en tant qu'académicien, il siégea à la commission de l'École. Plus tard, en mars 1872, il soutint de son influence politique les efforts pour loger l'École dans un édifice qui lui conviendrait.

23. Le 6 février 1860, trois jours après son élection à l'Académie des Inscriptions et Belles-Lettres, il fait une leçon inaugurale sur la peinture. Blanc \& Houssaye, 1860, p. 255, dans la Gazette des Beaux-Arts, ajoutent : « Heureux dans tout ce qu'il entreprend, le jeune et savant professeur a eu le bonheur de retrouver un discours de Périclès sur l'art dont il se propose de parler, et, à sa première leçon, il l'a traduit pour ses auditeurs. Cette lecture a produit sur eux le plus grand effet ». Ce texte est sans doute l'embryon mal compris de la pièce de théâtre Phidias, drame antique, dont il sera question plus bas. 
24. Beulé, 1858a, p. 6-7 (publié chez Firmin Didot, 23 pages).

25. Beulé, 1856a.

26. Adalbert de Beaumont prit une position opposée à celle de Beulé, contre les formes grecques ; sur ce débat, voir Darcel, 1863, p. 64, à propos de l'exposition universelle de Londres.

27. Le 8 janvier 1867, le vieux peintre donna une soirée chez lui : Mme Beulé y était invitée. La réception fut intime mais magnifique. Ingres fit jouer la musique des maîtres qu'il aimait, Haydn, Beethoven et Mozart. Ce fut la dernière fête; dans la nuit il tomba malade et mourut le 14 janvier : voir Blanc, 1870, 218-219.

28. Voir Beulé, 1860 (opuscule de 16 pages publié chez Firmin Didot).

29. Revue générale de l'architecture et des travaux publics 1856, p. 376. Voir les remarques de Br. Foucart dans Paris-Rome-Athènes 1982, p. 54.

30. Beulé, 1855, publié chez Firmin Didot.

31. Beulé, 1856b.

32. Beulé, 1857.

33. Beulé, $1858 \mathrm{~b}$. Cet ouvrage de 420 pages fut publié chez Rollin, rue Vivienne.

34. Beulé, 1873, vol. 2, p. 3-58, où il s'explique sur ces fouilles. Il aurait songé dès 1851 à faire des fouilles à Carthage. La publication est faite dans Beulé, 1861 (Imprimerie impériale). Il y revient sur la rivalité archéologique avec l'Angleterre à propos des fouilles de Carthage (p. 77-78) : " puisse l'exemple de l'Angleterre, qui vient d'enfouir une somme considérable dans le sol de Carthage, être tôt ou tard suivi! Seulement, on devra adopter un système tout opposé au système de M. Davis, qui ne cherchait que des objets propres à orner le Musée britannique. Ce sont les monuments eux-mêmes, leurs ruines mutilées mais instructives, les traces de la vieille cité phénicienne, presque effacées et si précieuses, les splendeurs de la colonie romaine, que n'ont pu détruire les dévastations de quinze siècles, c'est l'architecture, reflet fidèle de l'histoire d'un peuple, souvent aussi éloquentes que ses souvenirs, qui doit être le but de fouilles désintéressées. J'appelle fouilles désintéressées celles qu'on entreprend, non pour rapporter des objets antiques dont la valeur excède facilement ce qu'on a dépensé, mais pour faire reparaitre au jour une cité perdue, une civilisation oubliée, des édifices qui ne se peuvent transporter ".

35. Voir par exemple Gsell, 1920, p. 53-55, ou Lancel, 1992, p. 37-38 et 457-465. Sur les intentions de Beulé, voir ci-dessus.

36. Jean Lajard (1783-1858), académicien depuis mai 1830, avait notamment travaillé sur les cultes dans l'Empire romain ; Salomon Munk (1805-1867), né à Glogau en Prusse, avait travaillé à la Bibliothèque impériale. Voir Franqueville, 1895, p. 222-223 et 315.

37. CRAI, 1862a, p. 16-18, 33-37 et 149-151, voir aussi p. 169-170.

38. Intéressant article nécrologique de Blanc, 1861, à l'occasion de l'inauguration d'un monument en souvenir de Lenormant à Athènes.

39. CRAI, 1862a, p. 169.

40. Blanc \& Houssaye, 1861, p. 63.

41. Voir Gruyer, 1874, p. 86.

42. Signalons aussi l'Éloge de Meyerbeer, prononcé dans la séance du 28 octobre 1865.

43. On en prend connaissance par le dépouillement systématique des CRAI (par exemple CRAI, $1862 \mathrm{~b}, \mathrm{p} .92$, pour sa première nomination à la commission de l'École française, où il succède à Philippe Le Bas).

44. Lagrange, 1861, p.197-199; il y a même des attaques contre son érudition en archéologie grecque. Ces pages montrent bien comment la réforme des Beaux-Arts, dont nous parlerons dans quelques pas a été demandée et préparée par certains.

45. Beulé, 1862b, et Beulé, 1862c.

46. Beulé, 1863, chez Hachette. Une seconde édition date de 1869 (Beulé, 1869a), chez Didier et Compagnie. 
47. Beulé, 1869a, p. I. La préface s'achève par les mots qui suivent: "Que d'autres vantent la puissance de nos machines, notre industrie, le luxe de nos demeures, la variété de nos plaisirs. Pour moi, je le jure, je donnerai une vie entière, consumée dans ce tourbillon, où tout est vanité et fièvre, pour dix ans passés entre Périclès et Phidias ".

48. Beulé, 1868a (chez Didier et Compagnie). Une seconde édition en format plus réduit fut publiée en 1870.

49. Voir Nieuwerkerke, 2000, notamment Ph. Luez, «Intendant et surintendant des Beaux-Arts », p. 49-54.

50. Sur le maréchal Vaillant (1790-1872), voir la notice qui lui est consacrée dans Tulard (dir.), 1995, p. 1296-1297.

51. On voulait aussi que les architectes puissent bénéficier d'une formation administrative. Voir le dossier publié dans École impériale, 1863.

52. Elle fut reprise dans la première livraison de 1864 de la Gazette des Beaux-Arts: Documents, 1864, p. 267-273. La protestation commençait ainsi : "L'Académie, Sire, a remarqué avec un profond étonnement qu'elle n'était même pas nommée dans le rapport qui a provoqué le décret du 13 novembre » (p. 267).

53. L'opposition de l'Académie française fut particulièrement vive dès les lendemains du coup d'État et se manifesta par l'élection systématique d'opposants au régime : voir s.v. Académie Française, dans Tulard (dir.), 1995, p. 4, et Baguley, 2000, p. 78-79.

54. Nieuwerkerke, 2000, p. 51-53 (Ph. Luez). Viollet-le-Duc eut cependant l'impression d'avoir été mis dans une situation très désagréable par le comte de Nieuwerkerke et leurs relations s'en trouvèrent détériorées.

55. Documents, 1864, p. 273-287 (on peut penser que ce long texte, signé du ministre, le maréchal Vaillant, émanait en fait de Nieuwerkerke et de Viollet-le-Duc). Une phrase de cette réponse traduit bien la virulence des oppositions. Après avoir repris la question des prix de Rome, le ministre, continuait en effet: "Je pourrais clore ici l'examen des questions soulevées par les signataires de la protestation, car préoccupés seulement, on peut le croire, de la conservation de leurs privilèges, ils se sont abstenus de discuter les dispositions du décret du 13 novembre en ce qui touche l'enseignement ».

56. Documents, 1864, p. 288-291.

57. Voir le résumé rétrospectif de la querelle que Gruyer, 1874, p. 87, donne des événements.

58. Gruyer, 1874, p. 88.

59. Je ne connais cette affaire, à laquelle les notices nécrologiques consacrées à Beulé font allusion, que par le Hansard, séance des Communes du 7 mars 1867 (vol. 185, p. 1444-5).

60. Sur cette partie de l'activité de Napoléon III, voir Milza, 2004, p. 478-484, et Nicolet, 2003, p. 160-181. Voir aussi Baguley, 2000, p. 79-89.

61. Sur la constitution de cette équipe, voir Nicolet, 2003, p. 172-179.

62. Beulé, 1869b, p. 363-365.

63. Beulé, 1870 , p. 240-245 : «La faveur la plus insigne qu'il [Titus] pût demander était une mort prématurée. Il disparaissait à temps, avant la crise, avant le naufrage peut-être. Il avait régné deux ans, deux mois et vingt jours; mais si l'épreuve s'était prolongée, qui osera dire qu'il en serait sorti victorieux? » (citation p. 240-241).

64. Elles ne sont un peu plus nombreuses que dans le dernier volume de la série.

65. Par exemple, Beulé, 1869b, p. 122 : «Je vous demande la permission, messieurs, non pas de soutenir un paradoxe ... Je vous prierai même de faire un effort d'imagination ... ».

66. Beulé, $1869 \mathrm{~b}$, p. 302 et 310 . Si Beulé admire Britannicus, il n'estime pas Bérénice, pièce qu'il considère comme un monument de courtisanerie : Beulé, 1870, p. 139-140 et 226.

67. Beulé, 1867, p. 1-3.

68. Beulé, 1869b, p. 139 (voir aussi p. 236, Claude comparé aux frères des sultans qui se réfugient dans le harem). 
69. Beulé, 1869 b, p. 174.

70. Beulé, 1869b, p. 205 («La vie mécanique substituée à la vie politique a étendu sur tout le pays un réseau de rouages savants qui se transmettent le mouvement: un seul doigt imprime ce mouvement »).

71. Par exemple Beulé, 1867, p. 16 : «Si l'on veut se faire une idée exacte d'Auguste, il faut consulter, moins les écrivains qui l'ont flatté, que les artistes qui l'ont embelli aussi, mais qui l'ont copié ». Mais les quatre volumes du Procès des Césars sont totalement dépourvus d'illustrations, ce qui rend bien difficile la compréhension de l'analyse de ces œuvres d'art.

72. Beulé, 1869b, p. 214.

73. Beulé, 1867, p. 2. Voir aussi Beulé, 1868b, p. 153 : Beulé explique que l'histoire qu'il écrit intéressera « ceux qui subordonnent les faits à la morale ».

74. Suétone, Tibère, 24, cité dans Beulé, $1868 \mathrm{~b}, \mathrm{p} .57$.

75. Delord, 1876, t. 6, p. 9. Mais cet auteur ajoute, immédiatement après « M. Beulé parvint à son but, il fut un moment populaire, mais on sait aujourd'hui que le Juvénal de la Bibliothèque impériale, descendu de sa chaire, redevenu courtisan dans son cabinet, s'empressait d'écrire à César qu'il n'attaquait que ses ministres et qu'il lui gardait un dévouement et une reconnaissance inaltérable ».

76. Voir les remarques de Baguley, 2000, p. 77-89.

77. Nicolet, 2003, p. 154-159 notamment (mais voir aussi jusqu'à la p. 207).

78. Beulé, 1870, p. 110.

79. Beulé, 1870 : le titre est imprimé sur la première page de titre, non sur la page principale. Il y revient dans l'avertissement, p. VII : "Ainsi se complète un ouvrage composé désormais de quatre volumes : $1^{\circ}$ Auguste, sa famille et ses amis; $2^{\circ}$ Tibère et l'héritage d'Auguste; $3^{\circ}$ Le sang de Germanicus ; $4^{\circ}$ Titus et sa dynastie. On peut réunir les quatre volumes sous ce titre commun qui les caractérise nettement : Le procès des Césars ».

80. Dansette, 1972, p. 271-359, et Milza, 2004, p. 498-504.

81. Beulé, 1870, p. 36.

82. Milza, 2004, p. 554-558 et 566-569.

83. Dansette, 1972, p. 364-365.

84. Dansette, 1972, p. 334-338, et Milza, 2004, p. 552-554.

85. Beulé, 1868 b , p. 2-3. Cette idée d'un peuple finalement indigne de la liberté et qui a consenti à tout est très présente dans Beulé, 1869b, notamment à propos du personnage de Germanicus dont le peuple attend en vain qu'il restaure la république. Les gens de bien sont alors les victimes du pouvoir car ils sont trop peu nombreux pour se défendre (voir par ex. p. 61, « Dans les époques de corruption, les gens de bien qui n'ont pas osé prendre l'offensive doivent se résigner à de défendre et à n'être plus que des victimes »).

86. Beulé, 1868 b, p. 63 : le régime entraîne, quoi qu'il en soit, «l'avilissement de la nation qui subit une série d'échecs et d'opprobres ».

87. Beulé, 1869b, p. 165-169 : «Mais les peuples qui sont livrés au luxe, à la cupidité, à la mollesse, qui, pour mieux vaquer à leurs affaires privées ou à leurs plaisirs, ont abdiqué leurs droits et remis le glaive dans la main d'un seul maître, ils sauront trop tard ce qu'il en coûte et ils voudront trop tard rejeter une servitude qui n'est que l'expression de leur propre lâcheté ».

88. Beulé, 1869 b, p. 207.

89. Beulé, 1869 b, p. 88-89.

90. Beulé, 1870, p. 106.

91. Cité par Girard, 1986, p. 355-356.

92. Beulé, 1868b, p. 16-17.

93. Beulé, 1869b, p. 262.

94. Beulé, 1868b, p. 34. 
95. Beulé, 1869b, p. 236. Il y a une semblable allusion de Beulé aux liens qu'il entretient avec son public dans le cadre de ses cours de la Bibliothèque impériale lorsqu'il montre Tibère, pendant l'exil qui précède son arrivée au pouvoir, en train d'assister à des cours, « ce qui était à la mode sous l'empire, comme dans toutes les époques d'inaction politique et d'éloquence bâillonnée » (Beulé, 1868b, p. 136).

96. Beulé, 1867, p. 64.

97. Beulé, 1870, p. 320.

98. Beulé, 1870, p. 110, voir aussi p. 112 (« Le fétichisme impérial, si soigneusement développé par Auguste et par Livie, ressemble au souffle d'un enfant qui se joue avec une bulle de savon, légère, transparente, fragile et la soutien dans les airs. La bulle monte, descend, remonte encore et fait briller mille couleurs au soleil ; que l'enfant détourne la tête, elle crève aussitôt et tombe à terre. De même le peuple souffle sur de chétifs mortels, il les exalte jusqu'aux cieux par la force de son adoration ; mais, dès qu'il retient son haleine, l'idole se fond, le hochet s'évanouit, et les honnêtes gens se reprennent à espérer le règne des lois, de la morale et du bon sens »).

99. Beulé, 1870, p. 287.

100. L'affaire des gisants de Fontevraud lui avait toutefois permis de renouer le contact avec certaines des autorités locales.

101. Ideville, 1874.

102. Répondant à un questionnaire d'Henry d'Ideville, une dizaine d'années plus tôt, Beulé répondait «Périclès» à la question «Quel personnage ancien le plus sympathique? " et « Guizot » à la même question sur un personnage moderne.

103. Mémoires du duc de Broglie, 1938.

104. Le titre de président du Conseil n'est pas officiel avant 1876. Depuis 1871, on dit aussi bien «chef du gouvernement» que "président du conseil» ou "premier ministre » (avec des minuscules), voire ce « chef de cabinet » qui fait un peu rond-de-cuir.

105. Ideville, 1874.

106. Surnommés ainsi parce qu'ils se réunissaient Impasse des chevau-légers à Paris. Mais ce surnom leur allait très bien.

107. Mémoires du duc de Broglie, 1938.

108. Discours prononcé par le duc de Broglie sur la tombe de Beulé. Cité par Ideville, 1874.

109. Selon un rapport de René Bérenger, de décembre 1871, cité par Albert, 1980.

110. Ce ministre de Thiers est le fils du Premier ministre de Louis-Philippe et le père du Président de la République en 1894-1895.

111. De 1871 à 1879, les ministres sont à Versailles mais le gros de leur administration est resté à Paris, ce qui ne facilite pas le contrôle de la seconde par le premier.

112. Soyons justes: cette bévue a été commise deux après la démission de Beulé. Mais son successeur n'avait rien changé au fonctionnement du Bureau de la Presse.

113. Édition du 6-7 avril 1874.

114. Journal des débats, édition du 27 avril 1874. 


\section{AUTEURS}

\section{YVES BILLARD}

Maître de conférences en histoire contemporaine, Centre de Recherches Interdisciplinaires en Sciences humaines Et Sociales (CRISES, EA 4424), Université Paul Valéry - Montpellier III, Site Saint Charles, Rue du Professeur Henri Serre, 34090 Montpellier

\section{CHRISTOPHE CHANDEZON}

Professeur d'histoire grecque, Centre de Recherches Interdisciplinaires en Sciences humaines Et Sociales (CRISES, EA 4424), Université Paul Valéry - Montpellier III, Site Saint Charles, Rue du Professeur Henri Serre, 34090 Montpellier 